\title{
Optoelectronic and Birefringence Properties of Weakly Mg Doped ZnO Thin Ims Prepared By Spray Pyrolysis.
}

\section{Yassine Bouachibaa}

Laboratoire Technologie des Mat'eriaux Avanc'es

ABDELOUADOUD MAMMERI ( $\sim$ abdelouadoud.mammeri@gmail.com )

Laboratoire Couches Minces et Interfaces, Universit'e de Fr'eres Mentouri Constantine 1 https://orcid.org/0000-0003-3820-3324

\section{Abderrahmane Bouabellou}

Laboratoire Couches Minces et Interfaces, Universit'e de Fr'eres Mentouri Constantine 1

\section{Rabia Oualid}

Laboratoire Technologie des Mat'eriaux Avanc'es

\section{Saber Saidi}

Laboratoire Technologie des Mat'eriaux Avanc'es

Adel Taabouche

Universit'e de Fr'eres Mentouri Constantine 1

\section{Badis Rahal}

Nuclear Techniques Division, Nuclear Research Center of Algiers

\section{Lyes Benharrat}

Research Center in Semiconductors Technology for Energy-CRTSE

Hacene Serrar

Research Center in Industrial Technologies (CRTI)

\section{Moukhtar Boudissa}

University Ferhat Abbas

\section{Research Article}

Keywords: Optoelectronic, birefringence, $\mathrm{ZnO}$, pyrolysis

Posted Date: November 1st, 2021

DOI: https://doi.org/10.21203/rs.3.rs-1021475/v1

License: (c) (1) This work is licensed under a Creative Commons Attribution 4.0 International License. 



\section{Optoelectronic and birefringence properties of weakly $\mathrm{Mg}$ doped $\mathrm{ZnO}$ thin films prepared by spray pyrolysis}

\section{Yassine Bouachiba ${ }^{1}$, Abdelouadoud}

Mammeri $^{2 *}$, Abderrahmane Bouabellou ${ }^{2}$, Oualid Rabia $^{1}$, Saber Saidi ${ }^{1}$, Adel Taabouche ${ }^{2}$, Badis Rahal ${ }^{3}$, Lyes Benharrat $^{4}$, Hacene Serrar ${ }^{5}$ and Moukhtar Boudissa ${ }^{6}$

${ }^{1}$ Laboratoire Technologie des Matériaux Avancés,Ecole Nationale Polytechnique de Constantine Malek BENNABI,BP 75A RP,Ali Mendjeli, Constantine, Algérie.

${ }^{2 *}$ Laboratoire Couches Minces et Interfaces, Université de Fréres Mentouri Constantine 1, Constantine, Algérie.

${ }^{3}$ Nuclear Techniques Division, Nuclear Research Center of Algiers, 2 Bd, Frantz Fanon, BP 399, 16000, Algiers, Algeria.

${ }^{4}$ Research Center in Semiconductors Technology for Energy-CRTSE, 02, Bd. Dr. Frantz Fanon, B.P. 140,7 Merveilles, 16038, Algiers, Algeria.

${ }^{5}$ Research Center in Industrial Technologies (CRTI), BP 64 Cheraga, Alger, Algeria.

${ }^{6}$ ENMC Laboratory, Department of Physics, Faculty of Science, University Ferhat Abbas, Setif, 19000, Algeria.

*Corresponding author(s). E-mail(s):

abdelouadoud.mammeri@gmail.com;

Contributing authors: ybouachiba@gmail.com; a_ bouabellou@yahoo.fr; oualidrabia28@gmail.com; saber18saidi@gmail.com; adelphm@gmail.com; b.rahal@crna.dz;

benharrat.lyes@crtse.dz; serrarhacene@gmail.com; mokhtar.bousissa@univ-setif.dz; 


\section{Introduction}

Zinc Oxide $(\mathrm{ZnO})$ is is a multipurpose semiconductor with many uses such as ultra-capacitor electrode [1], spintronic devices [2], multigas sensing [3-6], piezoelectric devices [7], ultra-violet LEDs [8], detectors [9] as well as waveguides [10-12]. In its thin film form, $\mathrm{ZnO}$ has a large adaptation to several deposition methods such as chemical vapor deposition [13], pulsed laser deposition [14], spray pyrolysis [15], dip-coating [16] and electrochemical deposition [17]. $\mathrm{ZnO}$ has very interesting characteristics for application in electronics and optoelectronics devices, especially its exciton binding energy of $60 \mathrm{meV}$ at $300 \mathrm{~K}$, a wide direct band gap of $3.37 \mathrm{eV}$ [18]. In addition to an ordinary and extraordinary refractive indexes of $n_{e}=2.006$ and $n_{o}=1.990$ respectively [19]. To modify its electrical properties, $\mathrm{ZnO}$ was doped with Group III elements such as $\mathrm{Al}, \mathrm{Ga}$ and $\mathrm{In}$ which acted as donor dopants to reinforce its $n$-type electrical nature and group V elements such as N, P, As and Sb which acted as acceptor dopants which changed $\mathrm{ZnO}$ to be a $p$-type semiconductor [20]. Controlling the refractive index of $\mathrm{ZnO}$ thin films was achieved by several ways including thermal annealing [21] and doping with In [22], Te, $\mathrm{N}$ [23] and $\mathrm{Mg}$ [24]. However, the effect of dopants on the optical and electrical properties of $\mathrm{ZnO}$ is still not well understood.

Tailoring $\mathrm{ZnO}$ optical and electrical properties via dopants while maintaining high quality films especially using spray pyrolysis is very attractive to both scientists and technology developers as it offers a control over several experimental parameters, it is cheap, uncomplicated and environmentally friendly. Wurtzite $\mathrm{Mg}_{\mathrm{x}} \mathrm{Zn}_{1-\mathrm{x}} \mathrm{O}$ alloy is very interesting due to the high solubility of $\mathrm{Mg}$ in the $\mathrm{ZnO}$ wurtzite matrix (up to 30\%) [25]. Moreover, it offers control over a range of optical and electrical properties of $\mathrm{ZnO}$ such as widening of the optical gap energy up to $0.85 \mathrm{eV}$ [26], consequently, it can be used for multiple purposes such as a top layer in $\mathrm{Mg}_{\mathrm{x}} \mathrm{Zn}_{1-\mathrm{x}} \mathrm{O} / \mathrm{ZnO}$ multilayer UV photodetector [27] and high mobility $\mathrm{MgZnO} / \mathrm{ZnO}$ thin film transistor [28] to name few. Concerning the waveguiding properties, little attention has been paid to wurtzite $\mathrm{Mg}_{\mathrm{x}} \mathrm{Zn}_{1-\mathrm{x}} \mathrm{O}$ as a waveguide, however, $\mathrm{Mg}_{\mathrm{x}} \mathrm{Zn}_{1-\mathrm{x}} \mathrm{O}$ was used as a buffer layer for $\mathrm{ZnO}$ waveguide thin film [29]. In an other work, a potential use of $\mathrm{Mg}_{\mathrm{x}} \mathrm{Zn}_{1-\mathrm{x}} \mathrm{O}$ cubic rocksalt-type phase as a wave guide was reported $\mathrm{Yu}$ et al. [30]. Wurtzite $\mathrm{Mg}_{\mathrm{x}} \mathrm{Zn}_{1-\mathrm{x}} \mathrm{O}$ thin film alloy refractive index was previously studied but there is still work to be done, as there are opposite results regarding the birefringence which is found to be negative in some studies $[18,31]$ and positive in another study[24].

In this work, we engaged in the investigation of the relations between the refractive index, the optical gap energy and the charge carriers' density in addition to the birefringence of $\mathrm{Mg}_{\mathrm{x}} \mathrm{Zn}_{1-\mathrm{x}} \mathrm{O}$ thin films deposited by spray pyrolysis on glass substrate. 


\section{Results and Discussion}

\subsection{XRD analysis}

From Figure 1(a) we can see clearly that all films exhibit a crystalline hexagonal wurtzite structure (JCPDS card no. 00-036-1451) with the quasipredominance of (002) peak indicating the preferential growth of undoped and $\mathrm{Mg}$ doped $\mathrm{ZnO}$ thin films through the c-axis direction. However, weak intensity peaks of other crystallographic directions were observed in the following positions $31.96^{\circ}(100), 36.56^{\circ}(101), 47.87^{\circ}(102), 63.17^{\circ}(103)$ and $72.85^{\circ}(004)$. The peak (002) experienced a shift towards higher angles over Mg doping (Figure 1 (b)) which was reported by a number of authors [32-34] and it is due to the difference in the ionic radius between $\mathrm{Mg}^{+2}(0.57 \AA)$ and $\mathrm{Zn}^{+2}(0.60 \AA)$ [35]. This difference is directly related to the compression strain on the main axes of the wurtzite structure $a$ and $c$. Previously, Chang et al. [36] reported also similar compression strain in their sputtered MgZnO thin films which were interpreted by good substitution between $\mathrm{Mg}$ and $\mathrm{Zn}$ ions.

The grain size can be calculated by Debye-Scherrer formula [32]:

$$
D=\frac{K \lambda}{\beta \cos (\theta)}
$$

where $\lambda$ is the wavelength of the incident $\mathrm{X}$-ray, $\theta$ is the Bragg's angle, $\mathrm{K}$ is the shape factor ( 0.9 for gaussian fit) and $\beta$ is the Full Width at Half Maxima (FWHM) of the peaks. The crystallite size, lattice parameters and strain axes are tabulated in table 1 . It should be noted that there was no significant change in the average crystallite size $\left(33.13 \mathrm{~nm}\right.$ for $\mathrm{Mg}_{0} \mathrm{Zn}_{1} \mathrm{O}$ film and an average of $33.03 \mathrm{~nm}$ for the $\mathrm{Mg}_{\mathrm{x}} \mathrm{Zn}_{1-\mathrm{x}} \mathrm{O}$ films) and the minus sign of the strain values $\left(\epsilon_{a}\right.$ and $\left.\epsilon_{c}\right)$ approves the compression nature of the strain. To calculate lattice parameter $c$ of the thin films we used the Bragg's law (with $\mathrm{n}=1$ ) and the $d$ spacing of wurtzite structure.

\subsection{UV-Vis measurements}

The transmittance of the thin films was slightly enhanced on average with the introduction of $\mathrm{Mg}$ in the visible region $(400-800 \mathrm{~nm}$ ). The limit of the absorption zone was shifted to smaller wavelengths which renders the thin films to be more dielectric as $\mathrm{Mg}$ doping is increased, this effect is directly related to the blue shift of the optical band gap and it was approximated for each film using the Tauc's plot:

$$
\alpha h \nu=A\left(h \nu-E_{g}\right)^{n}
$$

where $h \nu$ is the photon energy, $E_{g}$ is the optical gap energy, A is constant and $n$ equals $\frac{1}{2}$ since $\mathrm{ZnO}$ has a direct band gap. The widening of the optical band gap could be ascribed to the difference in electronegativity between $\mathrm{Zn}^{+2}$ and $\mathrm{Mg}^{+2}$ ions [37-39]. In similar study, Al-Ghamdi [40] reported this correlation 
between the optical band gap energy and the electronegativity in his work about amorphous $\mathrm{Se}_{96-x} \mathrm{Te}_{4} \mathrm{Ag}_{\mathrm{x}}$ thin films.

In fact, it should be noted that both the electronegativity and electron affinity are directly related [41]. In this way Figure 4 presents the calculated optical band gap and the electron affinity versus $\mathrm{Mg}$ doping. The electron affinity $(e \chi)$ was quantitatively calculated using Vegard's law [42]:

$$
e \chi\left(M g_{x} Z n_{1-x} O\right)=e \chi(Z n O)-(e \chi(Z n O)-e \chi(M g O)) x
$$

$e \chi(Z n O), e \chi(M g O)$ have the value of $4.5 \mathrm{eV}$ [43] and $0.85 \mathrm{eV}$ [44] for the electron affinity of $\mathrm{ZnO}$ and $\mathrm{MgO}$ respectively. Previously, iskenderoglu et al. [25] approved experimentally by UPS technique the inverse relation between the optical gap energy and the electron affinity of sprayed $\mathrm{MgZnO}$ alloy thin film, with $\mathrm{Mg}$ doping ranging from 0 to $15 \%$.

\subsection{Photoluminescence}

The room temperature photoluminescence spectra are shown in Figure 5. The undoped thin film had four peaks at $381(3.25 \mathrm{eV}), 416(2.98 \mathrm{eV}), 441(2.81$ $\mathrm{eV})$ and $505 \mathrm{~nm}(2.46 \mathrm{eV})$ which were explained by: the emission corresponding to excitons recombination, zinc interstitial $\left(\mathrm{Zn}_{\mathrm{i}}\right)$, oxygen vacancies $\left(\mathrm{V}_{\mathrm{O}}\right)$ and donor $\mathrm{V}_{\mathrm{O}}$ - acceptor $\mathrm{V}_{\mathrm{Zn}}$ recombination respectively [45, 46]. The same peaks were observed also in $\mathrm{Mg}_{0.01} \mathrm{Zn}_{0.99} \mathrm{O}$ except a blue shift of the 380 peak to $381 \mathrm{~nm}(3.26 \mathrm{eV})$. The $\mathrm{Mg}_{0.03} \mathrm{Zn}_{0.97} \mathrm{O}$ thin film had three peaks 379 (3.27 $\mathrm{eV}), 416(2.81 \mathrm{eV})$ and $492 \mathrm{~nm}(2.52 \mathrm{eV})$ and they were attributed to excitons recombination, zinc interstitial $\left(\mathrm{Zn}_{\mathrm{i}}\right)$ [45] and oxygen vacancy $\left(\mathrm{V}_{\mathrm{O}}\right)$ [47] respectively. Finally the $\mathrm{Mg}_{0.05} \mathrm{Zn}_{0.95} \mathrm{O}$ thin film exhibited two peaks at 378 $(3.28 \mathrm{eV})$ and $503 \mathrm{~nm}(2.47 \mathrm{eV})$ and they were manifestations of excitons and donor $\mathrm{V}_{\mathrm{O}}$ - acceptor $\mathrm{V}_{\mathrm{Zn}}$ recombinations [45, 46]. The blue shift of the near band edge emission from the PL peaks was in consistency with the UV visible calculations of the optical band gap, however, it was at a lower rate which was explained by stokes shift [48].

\subsection{Electrical measurements}

Figure 6 demonstrates the near isotropic electric transportation of the deposited films which could be attributed to the fact that the films have the predominant orientation (002) of the wurtzite structure [49].

The free charge carriers' density decreased from $3.146 \times 10^{18}$ for the undoped film to $9.273 \times 10^{13} \mathrm{~cm}^{-3}$ for $\mathrm{Mg}_{0.05} \mathrm{Zn}_{0.95} \mathrm{O}$ film. In parallel, the resistivity increased from 109 to $1268 \Omega \mathrm{cm}$ and the mobility increased from 0.01821 to $53.08 \mathrm{~cm}^{2} /$ (V.s). The decreased charge carriers' density could be attributed to the fact that the conduction band (CB) of pure $\mathrm{ZnO}$ consists mainly of $\mathrm{O}_{2 \mathrm{p}}$ and $\mathrm{Zn}_{4 \mathrm{~s}}$ states $[50,51]$, so the introduction of $\mathrm{Mg}$ in $\mathrm{ZnO}$ thin films will reduce the $\mathrm{Zn}_{4 \mathrm{~s}}$ state and introduce $\mathrm{Mg}_{3 \mathrm{p}}$ state which has high energy relative to the $\mathrm{Zn}_{4 \mathrm{~s}}[52,53]$. Moreover, the widening in the optical bang gap energy 
discussed previously, could also influence the free charge carriers' density since the electrons passing from the valance band must requires higher energy to access the conduction band.

\subsection{Surface morphology}

Figure 8 shows the morphology of undoped and 5 at. \% doped $\mathrm{ZnO}$ thin films. The undoped (Figure 8(a)) thin film shows a dense surface with granular mixture of small grains and large aggregates. The size of the small grains varies from $\sim 20$ to $80 \mathrm{~nm}$ and that of the aggregates reaches $\sim 200-300 \mathrm{~nm}$. From the doped sample (Figure $8(\mathrm{~b})$ ), it is evident that magnesium has a tendency to promote the phenomenon of coalescence. This doped film shows a less dense and relatively homogeneous morphology with large aggregates whose size varies from $\sim 200$ to $500 \mathrm{~nm}$.

No cracks nor empty holes were observed on the surface of the films, revealing the high quality of our films.

\subsection{M-lines measurements}

The M-lines measurements demonstrated the guiding modes present in the films. All films had four guiding modes $\left(\mathrm{TE}_{0}, \mathrm{TE}_{1}, \mathrm{TM}_{0}\right.$, and $\left.\mathrm{TM}_{1}\right)$ two for each optical polarization (Transverse Electric mode (TE) and Transverse Magnetic mode (TM)) as illustrated in Figure 9. Using the dispersion equations for TE and TM polarizations, the optogeometric parameters can be calculated [54-56]. The effective indices, the films thicknesses and the birefringence values are presented in Table 2 .

Figure 10 illustrate the variation of $\mathrm{n}_{\mathrm{TE}}, \mathrm{n}_{\mathrm{TM}}$, optical gap energy and free charge carriers' density as a function of the $\mathrm{Mg}$ concentration. The slight difference between $n_{T M}$ and $n_{T E}$ confirmed the birefringence behavior of our films. This made the guided waves traveling during the TE mode in the plane perpendicular to the $c$-axis of the wurtzite structure submit to an ordinary refractive index $\left(\mathrm{n}_{\mathrm{TE}}\right)$ and during the TM mode to an extraordinary one $\left(\mathrm{n}_{\mathrm{TM}}\right)$ [19]. Both $\mathrm{n}_{\mathrm{TE}}$ and $\mathrm{n}_{\mathrm{TM}}$ were found to decreased over Mg doping. This behavior seems to be in good agreement with the broadening of the optical band gap and the depletion of the conduction band free charge carriers' (Figure 10) [57]. The birefringence was measured to be positive for all films which is a good indication for the unchanging orientations of the bonds $\mathrm{Zn}-\mathrm{O}$ with the replacement of $\mathrm{Zn}$ by $\mathrm{Mg}[58,59]$.

The inverse relation between the optical gap energy, the resistivity and the refractive index as $\mathrm{Mg}$ content increased in the $\mathrm{ZnO}$ thin film was also observed by Kaushal et al. [60]. The same fact has been reported by Teng et al. [24] for $\mathrm{Mg}$-doped $\mathrm{ZnO}$ thin films prepared by pulsed laser deposition. In similar study, Sorar et al. [61] found that the ordinary refractive index generally decreases with the increase of the $\mathrm{Si}$ doping in $\mathrm{ZnO}$ thin films prepared by sol-gel and annealed at $350{ }^{\circ} \mathrm{C}$ and $550{ }^{\circ} \mathrm{C}$ whereas their optical band gap energy was found to be blue shifted. 


\section{Tables}

\section{Figures}
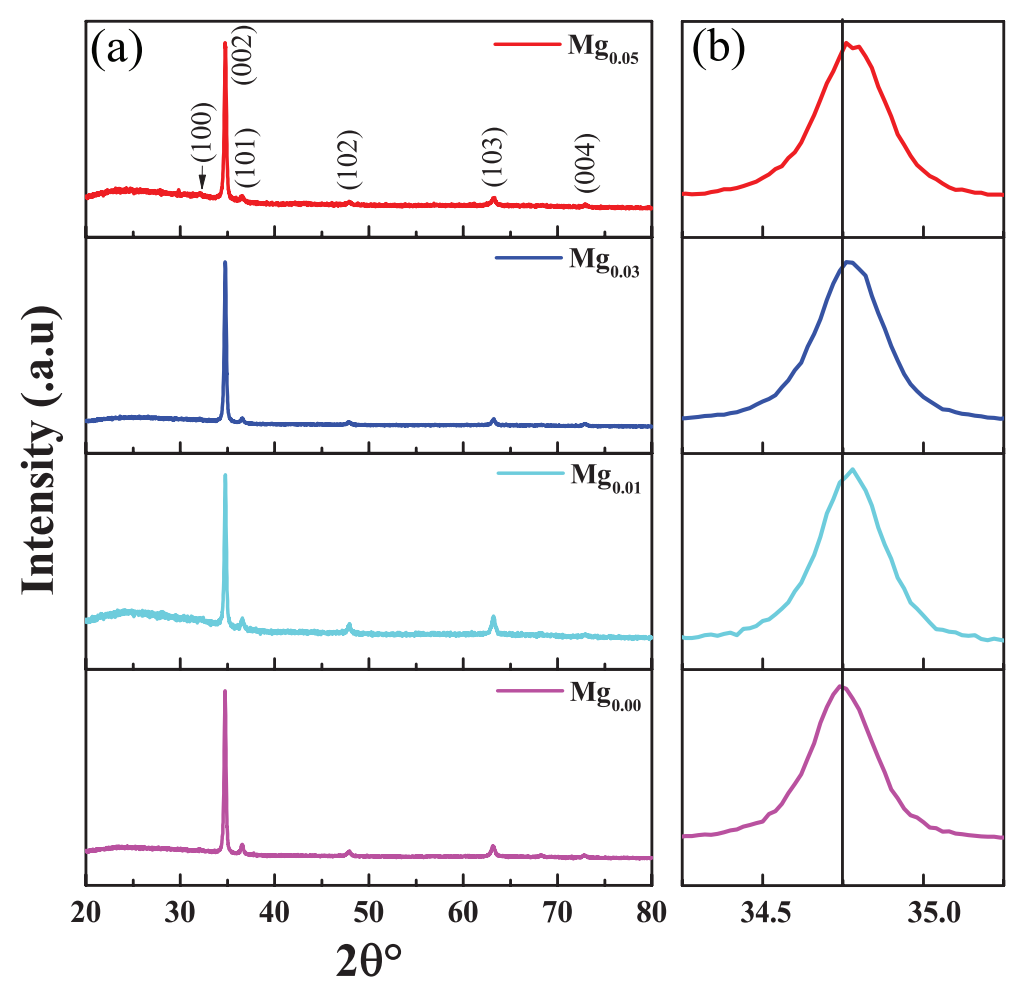

Fig. 1 (a) XRD spectra of undoped and $\mathrm{Mg}$ doped $\mathrm{ZnO}$ thin films, (b) an emphasis of the (002) peak showing a shift towards higher angles for the doped thin films.

\section{Methods}

The sprayed solution for the undoped $\mathrm{ZnO}$ thin films was prepared by dissolving the proper amount of dihydrate zinc acetate $\left[\mathrm{Zn}\left(\mathrm{CH}_{3} \mathrm{CO}_{2}\right)_{2} \cdot 2 \mathrm{H}_{2} \mathrm{O}\right]$ in $99.98 \%$ pure methanol to obtain $0.1 \mathrm{M}$ solution that was submitted to a constant stirring at $60{ }^{\circ} \mathrm{C}$ for $45 \mathrm{~min}$ on a magnetic stirrer. Concerning the sprayed solution of the $\mathrm{Mg}$ doped $\mathrm{ZnO}$ thin films, we maintained the same parameters with the use of magnesium chloride $\left[\mathrm{Mg}\left(\mathrm{CH}_{3} \mathrm{CO}_{2}\right)_{2} \cdot 4 \mathrm{H}_{2} \mathrm{O}\right]$ as $\mathrm{Mg}$ precursor and each time the proper amount was added to $0.1 \mathrm{M}$ methanol solutions of $\mathrm{Zn}\left(\mathrm{CH}_{3} \mathrm{CO}_{2}\right)_{2} \cdot 2 \mathrm{H}_{2} \mathrm{O}$ to produce the following contents of zinc and magnesium: $\mathrm{Mg}_{\mathrm{x}} \mathrm{Zn}_{1-\mathrm{x}} \mathrm{O}$ with $\mathrm{x}$ equals $0.01,0.03$ and 0.05 .

An ordinary glass substrate were ultra-sonically cleaned in a 1:1 mixture of acetone and ethanol for $15 \mathrm{~min}$ and left to dry in air. The films were deposited 
Table 1 The information obtained and calculated from the XRD spectra.

\begin{tabular}{|c|c|c|c|c|c|c|c|}
\hline Sample & $2 \theta$ (degree $)$ & $d$ spacing $(\AA)$ & Crystallite size (nm) & $a(\AA)$ & $c(\AA)$ & $\epsilon_{a}\left(10^{-3}\right)$ & $\epsilon_{c}\left(10^{-3}\right)$ \\
\hline $\mathrm{Mg}_{0.00} \mathrm{Zn}_{1.00} \mathrm{O}$ & 34.75 & 2.580 & 33.13 & 3.2306 & 5.1592 & -3.4241 & -5.4746 \\
\hline $\mathrm{Mg}_{0.01} \mathrm{Zn}_{0.99} \mathrm{O}$ & 34.77 & 2.455 & 31.26 & 3.2240 & 5.1560 & -5.4601 & -6.0915 \\
\hline $\mathrm{Mg}_{0.03} \mathrm{Zn}_{0.97} \mathrm{O}$ & 34.77 & 2.456 & 31.30 & 3.2256 & 5.1560 & -4.9665 & -6.0915 \\
\hline $\mathrm{Mg}_{0.05} \mathrm{Zn}_{0.95} \mathrm{O}$ & 34.78 & 2.577 & 35.83 & 3.2298 & 5.1547 & -3.6709 & -6.3421 \\
\hline
\end{tabular}


Table 2 Optogeometric Properties of the deposited thin films.

\begin{tabular}{|c|c|c|c|c|c|c|c|c|c|}
\hline \multirow{2}{*}{ Sample } & \multicolumn{4}{|c|}{ Effective index $\pm 10^{-4}$} & \multicolumn{2}{|c|}{ Refractive index $10^{-4}$} & \multirow{2}{*}{$\begin{array}{c}\text { Thickness TE } \\
\quad \pm 0.1 \mathrm{~nm}\end{array}$} & \multirow{2}{*}{$\begin{array}{c}\text { Thickness TM } \\
\quad \pm 0.1 \mathrm{~nm}\end{array}$} & \multirow{2}{*}{$\begin{array}{l}\text { Birefringence } \\
\left(\mathrm{n}_{\mathrm{TM}}-\mathrm{n}_{\mathrm{TE}}\right)\end{array}$} \\
\hline & $\mathrm{TE}_{0}$ & $\mathrm{TE}_{1}$ & $\mathrm{TM}_{0}$ & $\mathrm{TM}_{1}$ & $\mathrm{n}_{\mathrm{TE}}$ & $\mathrm{n}_{\mathrm{TM}}$ & & & \\
\hline $\mathrm{Mg}_{0.00} \mathrm{Zn}_{1} .00 \mathrm{O}$ & 1.8923 & 1.6565 & 1.8793 & 1.6033 & 1.9699 & 1.9761 & 436.1 & 452.1 & 0.0062 \\
\hline $\mathrm{Mg}_{0.01} \mathrm{Zn}_{0.99} \mathrm{O}$ & 1.8758 & 1.5994 & 1.8539 & 1.5486 & 1.9680 & 1.9682 & 347.4 & 382.6 & 0.0002 \\
\hline $\mathrm{Mg}_{0.03} \mathrm{Zn}_{0.97} \mathrm{O}$ & 1.8738 & 1.6203 & 1.8581 & 1.5647 & 1.9580 & 1.9652 & 413.1 & 426.3 & 0.0072 \\
\hline $\mathrm{Mg}_{0.05} \mathrm{Zn}_{0.95} \mathrm{O}$ & 1.8451 & 1.5981 & 1.8278 & 1.5494 & 1.9278 & 1.9314 & 417.7 & 433.7 & 0.0036 \\
\hline
\end{tabular}




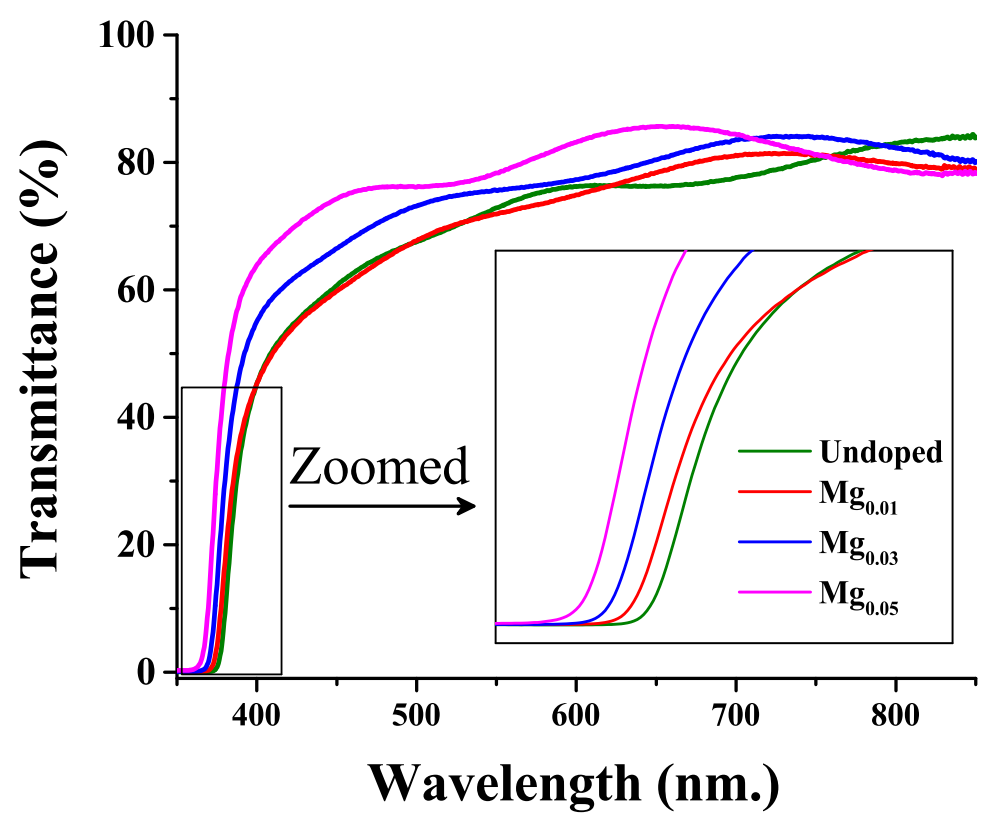

Fig. 2 Transmittance spectra of pure and doped $\mathrm{ZnO}$ thin films zoomed in the absorption region.

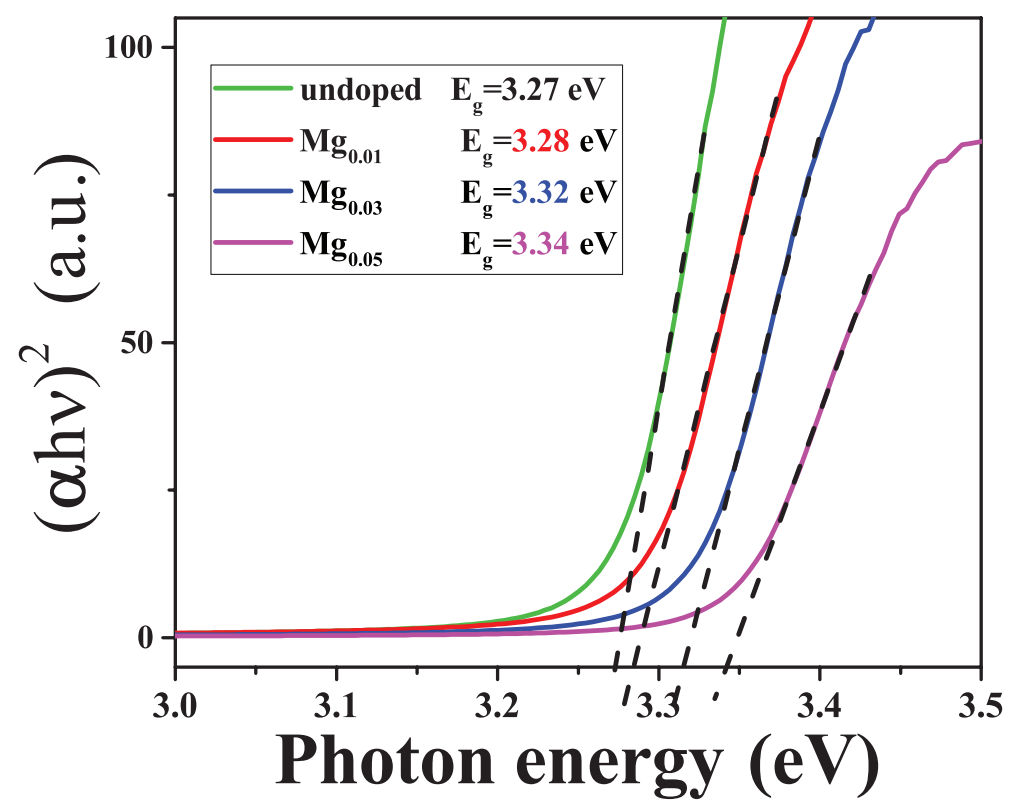

Fig. 3 Tauc's plot for the undoped and doped $\mathrm{ZnO}$ thin films. 


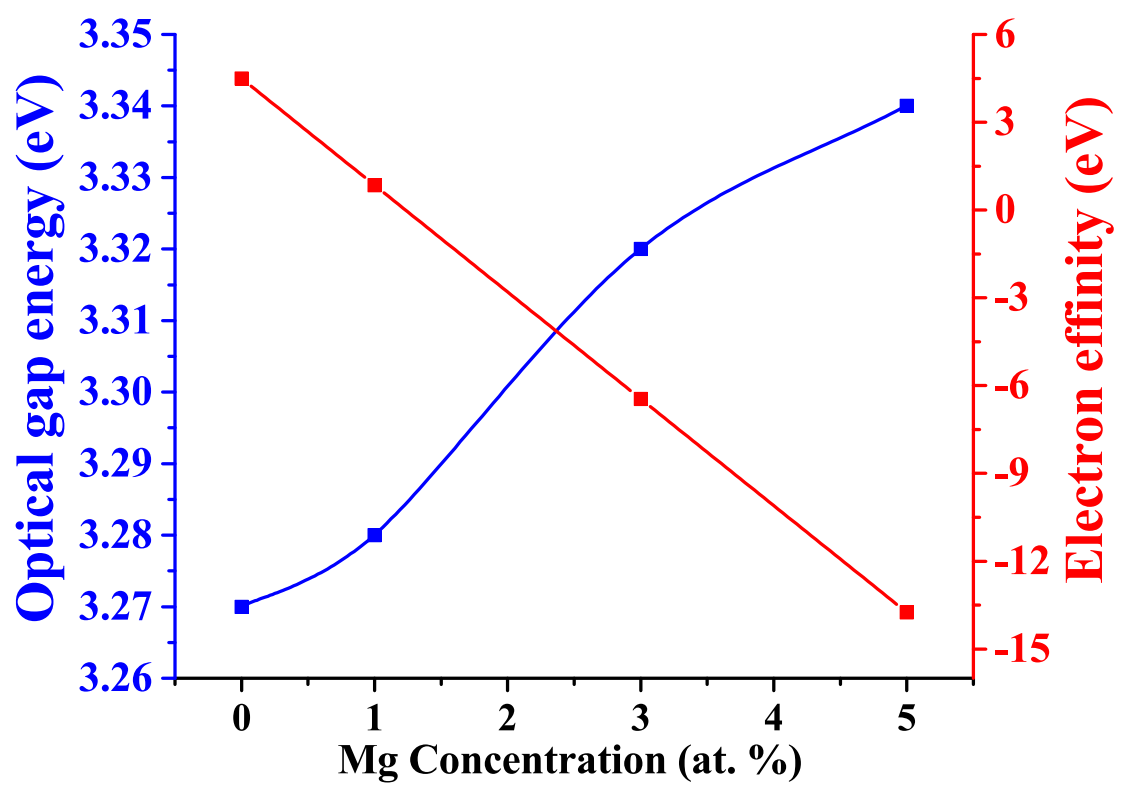

Fig. 4 The evolution of the optical band gap energy and the electron affinity of $\mathrm{Mg}_{\mathrm{x}} \mathrm{Zn}_{1-\mathrm{x}} \mathrm{O}$ thin films as a function of $\mathrm{Mg}$ concentration.
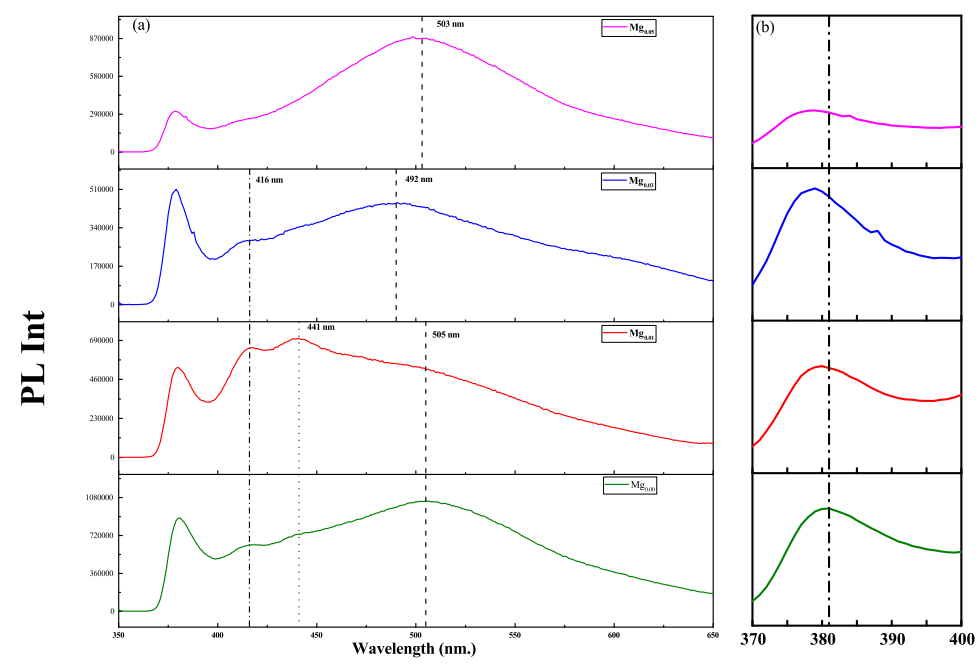

Fig. 5 (a) Room temperature photoluminescence spectra, (b) an emphasis of the excitons recombination peaks. 
Optoelectronic and birefringence properties of weakly $\mathrm{Mg}$ doped $\mathrm{ZnO}$ thin films prepared by s
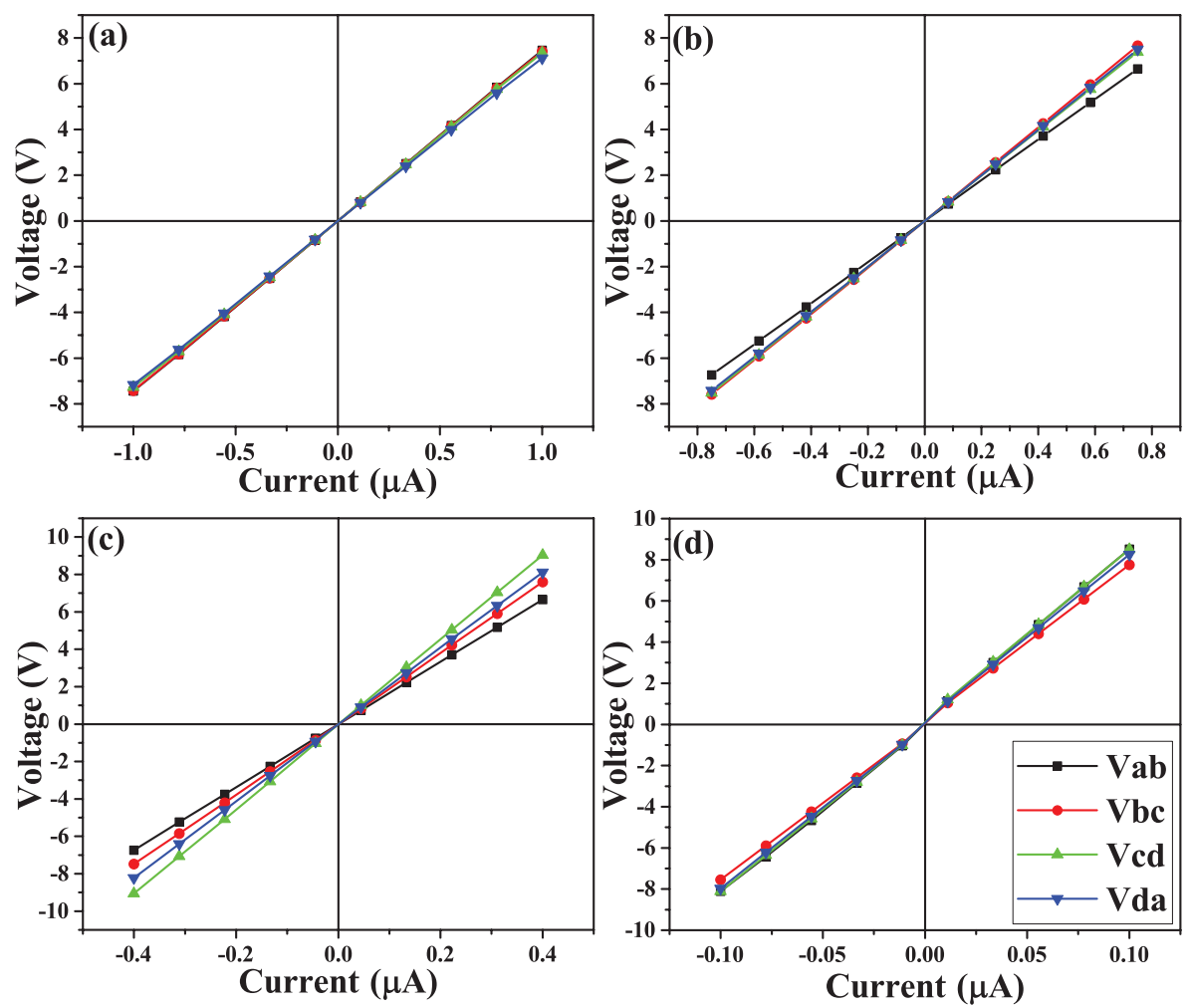

Fig. 6 I-V measurements for the four thin films: (a) undoped $\mathrm{ZnO}$, (b) $\mathrm{Mg}_{0.01} \mathrm{Zn}_{0.99} \mathrm{O}$, (c) $\mathrm{Mg}_{0.03} \mathrm{Zn}_{0.97} \mathrm{O}$ and $(\mathrm{d}) \mathrm{Mg}_{0.05} \mathrm{Zn}_{0.95} \mathrm{O}$.

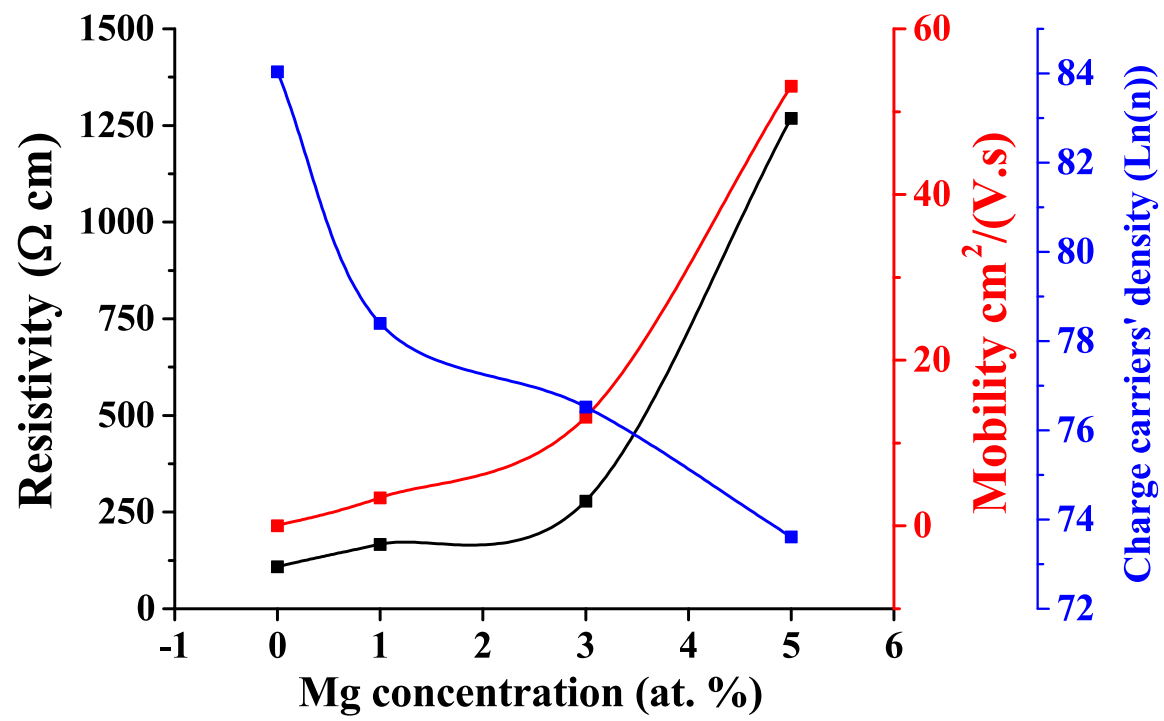

Fig. 7 Resistivity $(\rho)$ and charge carriers $(n)$ as a function of $\mathrm{Mg}$ concentration. 
using spray pyrolysis system. The deposition temperature was $450{ }^{\circ} \mathrm{C}$.

In order to characterize our thin films, multiple techniques were used: Philips PANalytical X'Pert Pro diffractometer with a wave length of $1.5406 \AA$, environmental scanning electron microscope Philips XL30 ESEM FEG and for the electrical properties Ecopia HMS-3000 hall effect measurement system, finally for the optical measurements, Metricon 2010/M Prism (rutile $\mathrm{TiO}_{2}: \mathrm{n}_{\mathrm{e}}=2,8639$ and $\mathrm{n}_{\mathrm{o}}=2.5822$ at $632,8 \mathrm{~nm}$ with an apical angle of $44,60^{\circ}$ ) Coupler was used to couple $632.8 \mathrm{~nm}$ HeNe laser light into air $/ \mathrm{Mg}_{\mathrm{x}} \mathrm{Zn}_{1-\mathrm{x}} \mathrm{O} /$ glass waveguide and Shimadzu UV-3101PC Spectrophotometer.

\section{Conclusion}

$\mathrm{Mg}$ doped $\mathrm{ZnO}$ thin films were successfully deposited on glass substrate via spray pyrolysis at $450{ }^{\circ} \mathrm{C}$. The XRD characterization showed highly $c$ oriented thin films with a decrease in $a$ and $c$ as the $\mathrm{Mg}$ concentration increased in the thin films. The undoped thin film had a multisize grain distribution meanwhile the $\mathrm{Mg}_{0.05} \mathrm{Zn}_{0.95} \mathrm{O}$ had a more homogeneous grain distribution. $\mathrm{Mg}$ doping in the $\mathrm{ZnO}$ films led to a blue shift of the optical band gap energy and a depletion of the conduction band due to the drop in free carriers' density that had a direct effect on the ordinary and the extraordinary refractive indexes that were found to decrease. The birefringence of a crystal depends on multiple factors such as strain, defects charge carriers' density, bounds orientations and so on, therefore it will change from papers to papers with the change of deposition method especially.

\section{Declarations}

- Funding: Not applicable

- Conflict of interest/Competing interests: The authors declare that they have no conflict of interest.

- Ethics approval: Not applicable

- Consent to participate: Not applicable

- Consent for publication: Not applicable

- Availability of data and materials: Not applicable

- Code availability: Not applicable

- Authors' contributions: Not applicable

\section{References}

[1] Lakshmi, K., Revathi, S.: Rice-like zno architecture: An eminent electrode material for high-performance ultracapacitor application. Journal of Inorganic and Organometallic Polymers and Materials 31(5), 1992-2002 (2021). https://doi.org/10.1007/s10904-021-01922-5

[2] Pearton, S., Norton, D., Heo, Y., Tien, L.-C., Ivill, M., Li, Y., Kang, B., Ren, F., Kelly, J., Hebard, A.: Zno spintronics and nanowire devices. 
Optoelectronic and birefringence properties of weakly $\mathrm{Mg}$ doped $\mathrm{ZnO}$ thin films prepared by

Journal of Electronic Materials 35, 862-868 (2006). https://doi.org/10. $1007 / \mathrm{BF} 02692541$

[3] Hosseinnejad, M.T., Shirazi, M., Ghoranneviss, M., Hantehzadeh, M.R., Darabi, E.: Preparation of nanostructured zno thin films using magnetron sputtering for the gas sensors applications. Journal of Inorganic and Organometallic Polymers and Materials 26(2), 405-412 (2016). https: //doi.org/10.1007/s10904-015-0324-0

[4] Hjiri, M., Bahanan, F., Aida, M., El Mir, L., Neri, G.: High performance co gas sensor based on zno nanoparticles. Journal of Inorganic and Organometallic Polymers and Materials 30(10), 4063-4071 (2020). https://doi.org/10.1007/s10904-020-01553-2

[5] Blauw, M., Dam, V.A., Crego-Calama, M., Brongersma, S., Musschoot, J., Detavernier, C.: Oxygen sensing with zno thin films. Proceedings of IEEE Sensors 28-31, 1416-1419 (2011). https://doi.org/10.1109/ ICSENS.2011.6127128

[6] Patil, V.L., Vanalakar, S.A., Patil, P.S., Kim, J.H.: Fabrication of nanostructured zno thin films based no2 gas sensor via silar technique. Sensors and Actuators B: Chemical 239, 1185-1193 (2017). https://doi.org/10. 1016/j.snb.2016.08.130

[7] Polewczyk, V., Maffei, R., Vinai, G., Cicero, M., Prato, S., Capaldo, P., Zilio, S., Bona, A., Paolicelli, G., Mescola, A., D’Addato, S., Torelli, P., Benedetti, S.: Zno thin films growth optimization for piezoelectric application. Sensors 21, 6114 (2021). https://doi.org/10.3390/s21186114

[8] Sandeep, K.M., Bhat, S., Dharmaprakash, S.M.: Structural, optical, and led characteristics of zno and al doped zno thin films. Journal of Physics and Chemistry of Solids 104, 36-44 (2017). https://doi.org/10.1016/j. jpcs.2017.01.003

[9] Shaikh, S., Ganbavle, V., Inamdar, S., Rajpure, K.: Multifunctional zinc oxide thin films for high performance uv photodetector and nitrogen dioxide gas sensor. RSC Adv. 6 (2016). https://doi.org/10.1039/ C6RA01750A

[10] Kamauchi, M., Shiosaki, T., Kawabata, A.: Channel optical waveguides of zno thin films. In: [Proceedings] 1990 IEEE 7th International Symposium on Applications of Ferroelectrics, pp. 733-736 (1990). https://doi.org/10. 1109/ISAF.1990.200361

[11] Yu, S.F., Yuen, C., Lau, S.P., Fan, W.J.: Design and fabrication of zinc oxide thin-film ridge waveguides on silicon substrate with ultraviolet amplified spontaneous emission. IEEE Journal of Quantum Electronics 
40(4), 406-412 (2004). https://doi.org/10.1109/JQE.2004.825212

[12] Teraoka, E., Kita, T., Tsukazaki, A., Kawasaki, M., Yamada, H.: Fabrication of zno channel waveguides for nonlinear optical applications. Proceedings of SPIE - The International Society for Optical Engineering 7940 (2011). https://doi.org/10.1117/12.874439

[13] Chen, Z., Shum, K., Salagaj, T., Zhang, W., Strobl, K.: Zno thin films synthesized by chemical vapor deposition, pp. 1-6 (2010). https://doi. org/10.1109/LISAT.2010.5478331

[14] Shan, F.K., Shin, B.C., Jang, S.W., Yu, Y.S.: Substrate effects of zno thin films prepared by pld technique. Journal of the European Ceramic Society 24(6), 1015-1018 (2004). https://doi.org/10.1016/S0955-2219(03) 00397-2. Electroceramics VIII

[15] Lehraki, N., Aida, M.S., Abed, S., Attaf, N., Attaf, A., Poulain, M.: Zno thin films deposition by spray pyrolysis: Influence of precursor solution properties. Current Applied Physics 12(5), 1283-1287 (2012). https:// doi.org/10.1016/j.cap.2012.03.012

[16] Rahal, B., Boudine, B., Larbah, Y., Siad, M., Souami, N.: Influence of low cd-doping concentration (0.5 and 3 wt.\%) and different substrate types (glass and silicon) on the properties of dip-coated nanostructured zno semiconductors thin films. Journal of Inorganic and Organometallic Polymers and Materials, 1-17 (2021). https://doi.org/10. 1007/s10904-021-02024-y

[17] Hamidi, A.S., Abidin, M.S.Z.: Electrochemical deposition of zinc oxide thin film using two-terminal setup. In: 2017 IEEE Regional Symposium on Micro and Nanoelectronics (RSM), pp. 34-37 (2017). https://doi.org/ 10.1109/RSM.2017.8069136

[18] Ellmer, K., Klein, A., Rech, B. (eds.): Transparent Conductive Zinc Oxide: Basics and Applications in Thin Film Solar Cells. Springer series in materials science, vol. 104. Springer, Berlin (2008). OCLC: ocn181423059

[19] Mehan, N., Tomar, M., Gupta, V., Mansingh, A.: Optical waveguiding and birefringence properties of sputtered zinc oxide (zno) thin films on glass. Optical Materials 27(2), 241-248 (2004). https://doi.org/10.1016/ j.optmat.2004.03.005

[20] Jagadish, C., Pearton, S.J.: Zinc Oxide Bulk, Thin Films and Nanostructures: Processing, Properties, and Applications vol. 7. Elsevier, ??? (2011)

[21] Huang, B., Li, J., Wu, Y.-b., Guo, D.-h., Wu, S.-t.: Optical constants of 
Optoelectronic and birefringence properties of weakly $\mathrm{Mg}$ doped $\mathrm{ZnO}$ thin films prepared by s

transparent zno films by rf magnetron sputtering. Materials Letters 62(8), 1316-1318 (2008). https://doi.org/10.1016/j.matlet.2007.08.043

[22] Xie, G.C., Fanga, L., Peng, L.P., Liu, G.B., Ruan, H.B., Wu, F., Kong, C.Y.: Effect of In-doping on the Optical Constants of ZnO Thin Films. Physics Procedia 32, 651-657 (2012). https://doi.org/10.1016/j.phpro. 2012.03.614. Accessed 2021-07-23

[23] Cai, A.L., Muth, J.F., Porter, H.L., Kvit, A., Narayan, J.: The refractive index and other properties of doped zno films. MRS Proceedings 764, 3-21 (2003). https://doi.org/10.1557/PROC-764-C3.21

[24] Teng, C., Muth, J., Ozgur, U., Bergmann, M., Everitt, H., Sharma, A., Jin, C., Narayan, J.: Refractive indices and absorption coefficients of mgxzn1-xo alloys. Applied Physics Letters 76, 979-981 (2000). https: //doi.org/10.1063/1.125912

[25] iskenderoglu, D., Kasapoglu, A., Gür, E.: Valance band properties of mgzno thin films with increasing mg content; phase separation effects. Materials Research Express 6 (2018). https://doi.org/10.1088/2053-1591/ aaf45e

[26] Özgür, ., Alivov, Y.I., Liu, C., Teke, A., Reshchikov, M.A., Doğan, S., Avrutin, V., Cho, S.-J., Morkoç, H.: A comprehensive review of zno materials and devices. Journal of Applied Physics 98(4), 041301 (2005) https://arxiv.org/abs/https://doi.org/10.1063/1.1992666. https: //doi.org/10.1063/1.1992666

[27] Rana, V.S., Rajput, J.K., Pathak, T.K., Purohit, L.P.: Multilayer mgzno/zno thin films for uv photodetectors. Journal of Alloys and Compounds 764, 724-729 (2018). https://doi.org/10.1016/j.jallcom.2018.06. 139

[28] Yue, D., Guo, S., Han, S., Cao, P., Zeng, Y., Xu, W., Fang, M., Liu, W., Zhu, D., Lu, Y., Qian, Y.: Facile fabrication of mgzno/zno composites for high performance thin film transistor. Journal of Alloys and Compounds 873, 159840 (2021). https://doi.org/10.1016/j.jallcom.2021.159840

[29] Jia, C.-L., Wang, K.-M., Wang, X.-L., Zhang, X.-J., Lu, F.: Formation of c-axis oriented zno optical waveguides by radio-frequency magnetron sputtering. Optics express 13, 5093-9 (2005). https://doi.org/10.1364/ OPEX.13.005093

[30] Yu, P., Wu, H.Z., Xu, T.N., Qiu, D.J., Hu, G.J., Dai, N.: Cubic phase mgxzn1-xo thin films for optical waveguides. Journal of Crystal Growth 310(2), 336-340 (2008). https://doi.org/10.1016/j.jcrysgro.2007.10.028 
[31] Morkoç, H., Özgür, m.: Zinc Oxide: Fundamentals, Materials and Device Technology, 1st edn. Wiley, ??? (2009). https://doi.org/10. 1002/9783527623945. https://onlinelibrary.wiley.com/doi/book/10.1002/ 9783527623945 Accessed 2021-07-26

[32] Khorramshahi, V., Karamdel, J., Yousefi, R.: Acetic acid sensing of Mg-doped $\mathrm{ZnO}$ thin films fabricated by the sol-gel method. Journal of Materials Science: Materials in Electronics 29(17), 14679-14688 (2018). https://doi.org/10.1007/s10854-018-9604-0. Accessed 2021-06-18

[33] Kim, T.H., Park, J.J., Nam, S.H., Park, H.S., Cheong, N.R., Song, J.K., Park, S.M.: Fabrication of Mg-doped $\mathrm{ZnO}$ thin films by laser ablation of Zn:Mg target. Applied Surface Science 255(10), 5264-5266 (2009). https: //doi.org/10.1016/j.apsusc.2008.07.105. Accessed 2021-06-18

[34] Shan, F.K., Kim, B.I., Liu, G.X., Liu, Z.F., Sohn, J.Y., Lee, W.J., Shin, B.C., Yu, Y.S.: Blueshift of near band edge emission in $\mathrm{Mg}$ doped $\mathrm{ZnO}$ thin films and aging. Journal of Applied Physics 95(9), 4772-4776 (2004). https://doi.org/10.1063/1.1690091. Accessed 2021-06-18

[35] Rouchdi, M., Salmani, E., Fares, B., Hassanain, N., Mzerd, A.: Synthesis and characteristics of $\mathrm{Mg}$ doped $\mathrm{ZnO}$ thin films: Experimental and abinitio study. Results in Physics 7, 620-627 (2017). https://doi.org/10. 1016/j.rinp.2017.01.023. Accessed 2021-06-18

[36] Chang, R.-C., Chu, S.-Y., Yeh, P.-W., Hong, C.-S., Kao, P.-C., Huang, Y.-J.: The influence of $\mathrm{Mg}$ doped $\mathrm{ZnO}$ thin films on the properties of Love wave sensors. Sensors and Actuators B: Chemical 132(1), 290-295 (2008). https://doi.org/10.1016/j.snb.2008.01.038. Accessed 2021-06-18

[37] Hussain, F., Imran, M., Khalil, R.M.A., Niaz, N.A., Rana, A.M., Sattar, M.A., Ismail, M., Majid, A., Kim, S., Iqbal, F., Javid, M.A., Saeed, S., Sattar, A.: An insight of $\mathrm{Mg}$ doped $\mathrm{ZnO}$ thin films: A comparative experimental and first-principle investigations. Physica E: Low-dimensional Systems and Nanostructures 115, 113658 (2020). https://doi.org/10. 1016/j.physe.2019.113658. Accessed 2021-06-18

[38] Huang, K., Tang, Z., Zhang, L., Yu, J., Lv, J., Liu, X., Liu, F.: Preparation and characterization of $\mathrm{Mg}$-doped $\mathrm{ZnO}$ thin films by sol-gel method. Applied Surface Science 258(8), 3710-3713 (2012). https://doi.org/10. 1016/j.apsusc.2011.12.011. Accessed 2021-06-18

[39] Agrawal, A., Dar, T.A., Sen, P., Phase, D.M.: Transport and magnetotransport study of $\mathrm{Mg}$ doped $\mathrm{ZnO}$ thin films. Journal of Applied Physics 115(14), 143701 (2014). https://doi.org/10.1063/1.4870864. Accessed 2021-06-18 
[40] Al-Ghamdi, A.A.: Optical band gap and optical constants in amorphous Se96-xTe4Agx thin films. Vacuum 80(5), 400-405 (2006). https://doi.org/ 10.1016/j.vacuum.2005.07.003. Accessed 2021-09-18

[41] Mulliken, R.S.: A New Electroaffinity Scale; Together with Data on Valence States and on Valence Ionization Potentials and Electron Affinities. The Journal of Chemical Physics 2(11), 782-793 (1934). https: //doi.org/10.1063/1.1749394. Accessed 2021-09-17

[42] Vegard, L.: Die konstitution der mischkristalle und die raumfüllung der atome. Zeitschrift für Physik 5(1), 17-26 (1921)

[43] Hussain, B., Aslam, A., Khan, T.M., Creighton, M., Zohuri, B.: Electron affinity and bandgap optimization of zinc oxide for improved performance of zno/si heterojunction solar cell using pc1d simulations. Electronics $\mathbf{8}(2), 238(2019)$

[44] Aboelfotoh, M.O., Lorenzen, J.A.: Influence of secondary-electron emission from mgo surfaces on voltage-breakdown curves in penning mixtures for insulated-electrode discharges. Journal of Applied Physics 48(11), 4754-4759 (1977) https://arxiv.org/abs/https://doi.org/ 10.1063/1.323490. https://doi.org/10.1063/1.323490

[45] Mishra, S., Srivastava, R., Prakash, S., Yadav, R., Panday, A.: Photoluminescence and photoconductive characteristics of hydrothermally synthesized zno nanoparticles. Opto-Electronics Review 18(4), 467-473 (2010)

[46] Chen, H., Ding, J., Guo, W., Chen, G., Ma, S.: Blue-green emission mechanism and spectral shift of al-doped zno films related to defect levels. RSC Adv. 3, 12327-12333 (2013). https://doi.org/10.1039/C3RA40750K

[47] Babu, K.S., Reddy, A.R., Sujatha, C., Reddy, K.V., Mallika, A.: Synthesis and optical characterization of porous zno. Journal of Advanced Ceramics 2(3), 260-265 (2013)

[48] Kim, T.H., Park, J.J., Nam, S.H., Park, H.S., Cheong, N.R., Song, J.K., Park, S.M.: Fabrication of mg-doped zno thin films by laser ablation of zn: Mg target. Applied Surface Science 255(10), 5264-5266 (2009)

[49] Oliveira, M., Castro, A., Marques, M., Rubio, A.: On the use of neumann's principle for the calculation of the polarizability tensor of nanostructures. Journal of nanoscience and nanotechnology 8, 3392-8 (2008). https://doi. org/10.1166/jnn.2008.142

[50] Hu, Y., Zeng, H., Du, J., Hu, Z., Zhang, S.: The structural, electrical and optical properties of mg-doped $\mathrm{ZnO}$ with different interstitial $\mathrm{mg}$ 
concentration. Materials Chemistry and Physics 182, 15-21 (2016). https: //doi.org/10.1016/j.matchemphys.2016.05.065. Accessed 2021-06-29

[51] Bustanafruz, F., Fazli, M., Mohammadizadeh, M.R., Jafar Tafreshi, M.: Optical and electronic properties of h-doped $\mathrm{ZnO}$. Optical and Quantum Electronics 48(5), 297 (2016). https://doi.org/10.1007/ s11082-016-0575-1. Accessed 2021-06-29

[52] Wang, J., Tu, Y., Yang, L., Tolner, H.: Theoretical investigation of the electronic structure and optical properties of zinc-doped magnesium oxide. Journal of Computational Electronics 15, 1521-1530 (2016). https://doi. org $/ 10.1007 /$ s10825-016-0906-2

[53] Zheng, W., Feng, Z.C., Chang, F.H., Lee, J.F., Zheng, R.S., Wuu, D.S., Liu, C.W.: Study of $\mathrm{Mg}_{\mathrm{x}} \mathrm{Zn}_{1-\mathrm{x}} \mathrm{O}$ Alloys $(0<\mathrm{x}<0.15)$ by X-Ray Absorption Spectroscopy. Advanced Materials Research 663, 361-365 (2013). https:// doi.org/10.4028/www.scientific.net/AMR.663.361. Accessed 2021-07-29

[54] Bouachiba, Y., Taabouche, A., Bouabellou, A., Hanini, F., Sedrati, C., Merabti, H.: Tio waveguides thin films prepared by sol-gel method on glass substrates with and without zno underlayer. Materials Science-Poland 38(3), 381-385 (2020). https://doi.org/10.2478/msp-2020-0043

[55] Medjaldi, F., Bouabellou, A., Bouachiba, Y., Taabouche, A., Bouatia, K., Serrar, H.: Study of $\mathrm{TiO} 2, \mathrm{SnO} 2$ and nanocomposites $\mathrm{TiO} 2 \mathrm{SnO} 2$ thin films prepared by sol-gel method: Successful elaboration of variable-refractive index systems $\mathbf{7}(1), 016439$ (2020). https://doi.org/10. 1088/2053-1591/ab6c0c

[56] Gharbi, B., Taabouche, A., Brella, M., Gheriani, R., Bouachiba, Y., Bouabellou, A., Hanini, F., Barouk, S.L., Serrar, H., Rahal, B.: Spray pyrolysis synthesized and zno-nio nanostructured thin films analysis with their nanocomposites for waveguiding applications. Semiconductors 55, 37-43 (2021)

[57] Feynman, R.P., Leighton, R.B., Sands, M.: The Feynman Lectures on Physics; New Millennium Ed. Basic Books, New York, NY (2010). Originally published 1963-1965. https://cds.cern.ch/record/1494701

[58] Weber, H.-J.: Anisotropic bond polarizabilities in birefringent crystals. Acta Crystallographica Section A 44(3), 320-326 (1988). https://doi.org/ 10.1107/S0108767387012492

[59] Lidin, S.: Mapping bond orientations with polarized x-rays. Science 344(6187), 969-970 (2014). https://doi.org/10.1126/science.1254902

[60] Kaushal, A., Kaur, D.: Effect of mg content on structural, electrical and 
Optoelectronic and birefringence properties of weakly $\mathrm{Mg}$ doped $\mathrm{ZnO}$ thin films prepared by s

optical properties of zn1-xmgxo nanocomposite thin films. Solar Energy Materials and Solar Cells 93, 193-198 (2009). https://doi.org/10.1016/j. solmat.2008.09.039

[61] Sorar, I., Saygin-Hinczewski, D., Hinczewski, M., Tepehan, F.Z.: Optical and structural properties of si-doped zno thin films. Applied Surface Science 257(16), 7343-7349 (2011). https://doi.org/10.1016/j.apsusc.2011. 03.142 

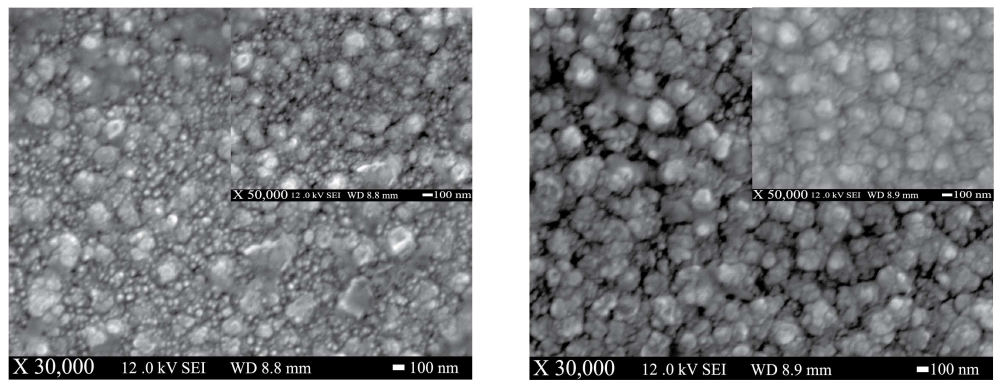

Fig. 8 (left) SEM images of the undoped $\mathrm{ZnO}$ thin film, (right) SEM images of the $\mathrm{Zn}_{0.95} \mathrm{Mg} 0.05 \mathrm{O}$ thin films at $30 \mathrm{k} \times$ and $50 \mathrm{k} \times$, big and small picture respectively. 

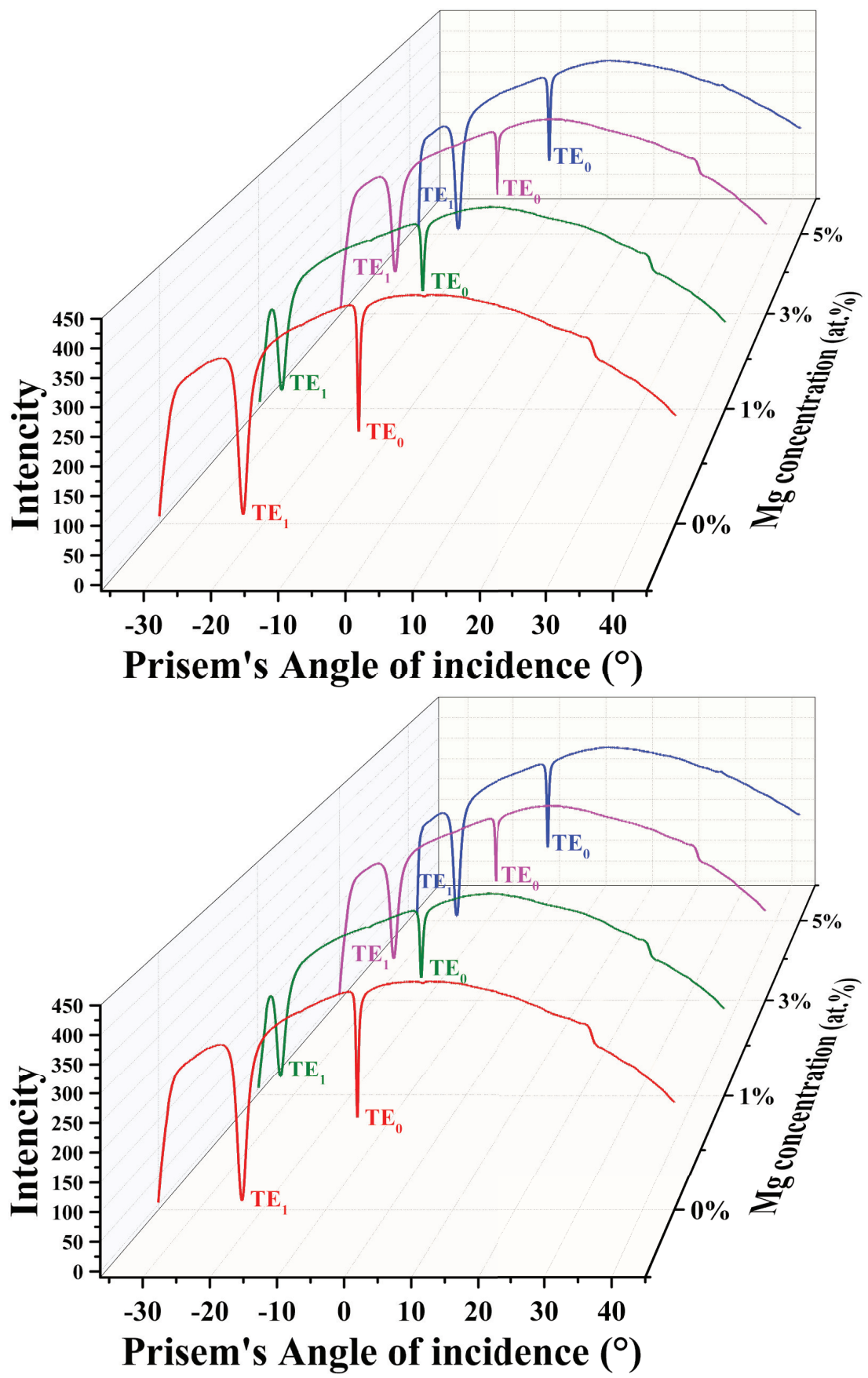

Fig. 9 M-lines intensity vs angle of incident for the deposited doped and undoped films in both Transverse Electric (TE) and Transverse Magnetic (TM). 

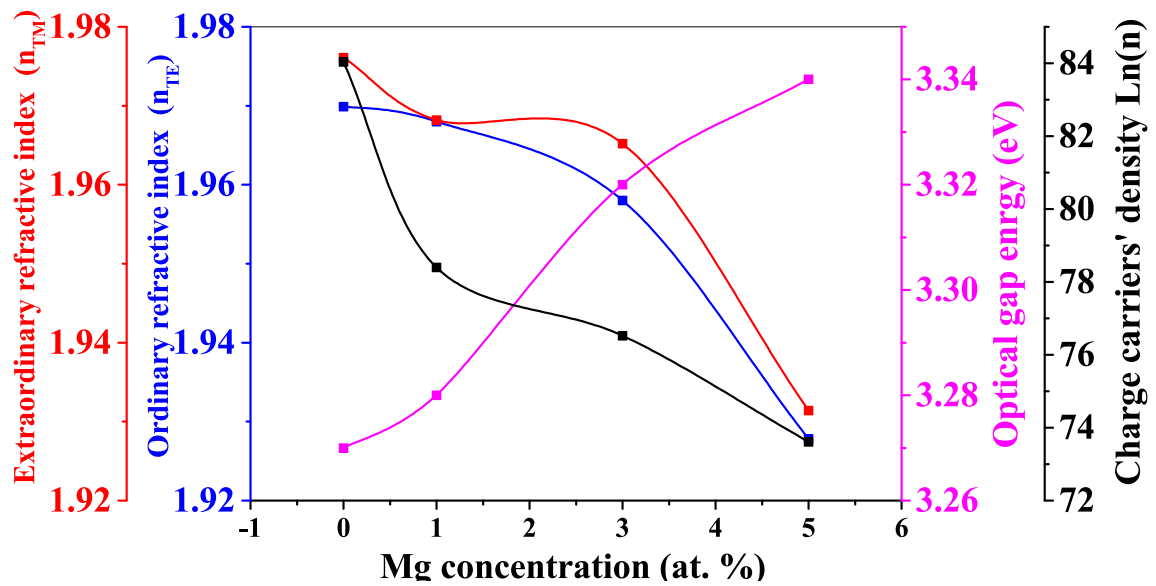

Fig. 10 Ordinary $\left(\mathrm{n}_{\mathrm{TE}}\right)$ and extraordinary $\left(\mathrm{n}_{\mathrm{TM}}\right)$ refractive indices, optical gap energy and charge carriers' density as a function of $\mathrm{Mg}$ concentration. 

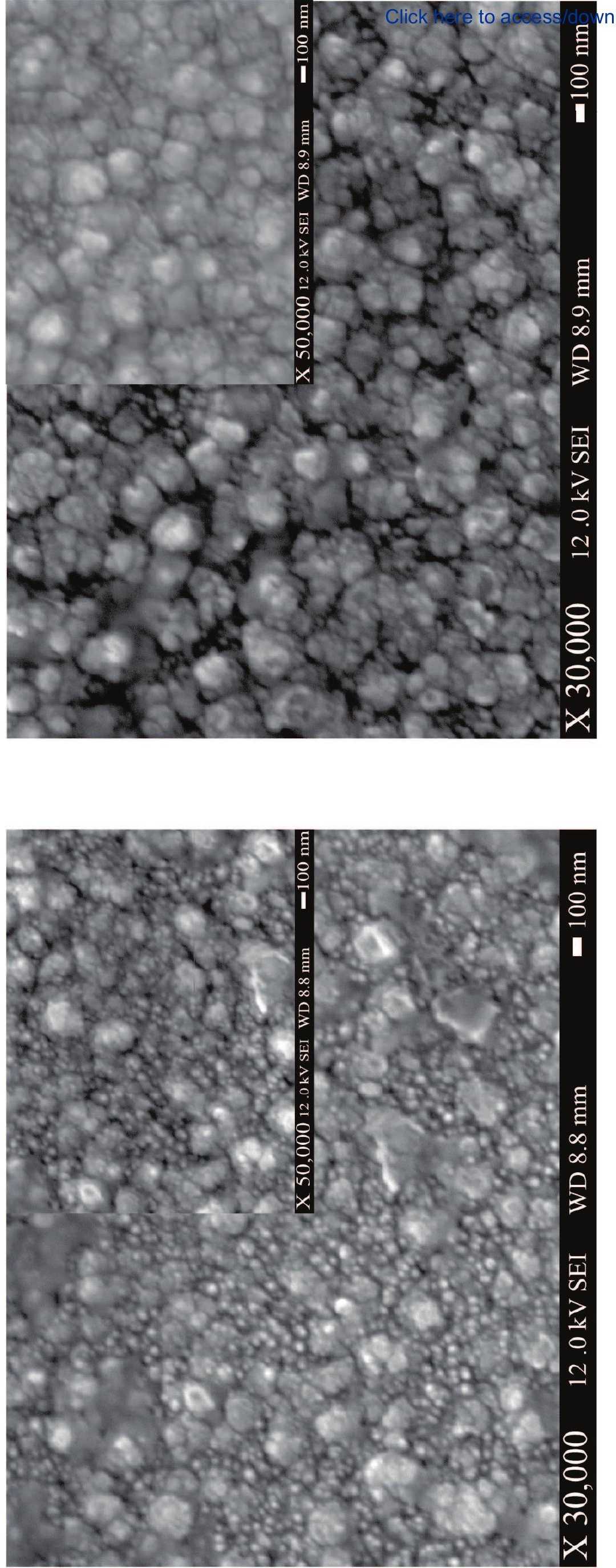


\section{Optoelectronic and birefringence properties of weakly $\mathrm{Mg}$ doped $\mathrm{ZnO}$ thin films prepared by spray pyrolysis}

Yassine Bouachiba ${ }^{1}$, Abdelouadoud Mammeri $^{*}$, Abderrahmane Bouabellou ${ }^{1}$, Oualid Rabia $^{1}$, Saber Saidi ${ }^{1}$, Adel Taabouche ${ }^{1}$, Badis Rahal ${ }^{1}$, Lyes Benharrat $^{1}$, Hacene Serrar ${ }^{1}$ and Moukhtar Boudissa ${ }^{1}$

${ }^{1}$ Laboratoire Technologie des Matériaux Avancés,Ecole Nationale Polytechnique de Constantine Malek BENNABI,BP 75A RP,Ali Mendjeli, Constantine, Algérie.

${ }^{2 *}$ Laboratoire Couches Minces et Interfaces, Université de Fréres Mentouri Constantine 1, Constantine, Algérie.

${ }^{3}$ Nuclear Techniques Division, Nuclear Research Center of Algiers, 2 Bd, Frantz Fanon, BP 399, 16000, Algiers, Algeria.

${ }^{4}$ Research Center in Semiconductors Technology for Energy-CRTSE, 02, Bd. Dr. Frantz Fanon, B.P. 140,7 Merveilles, 16038, Algiers, Algeria.

${ }^{5}$ Research Center in Industrial Technologies (CRTI), BP 64 Cheraga, Alger, Algeria.

${ }^{6}$ ENMC Laboratory, Department of Physics, Faculty of Science, University Ferhat Abbas, Setif, 19000, Algeria.

${ }^{*}$ Corresponding author(s). E-mail(s):

abdelouadoud.mammeri@gmail.com;

Contributing authors: ybouachiba@gmail.com; a_ bouabellou@yahoo.fr; oualidrabia28@gmail.com; saber18saidi@gmail.com; adelphm@gmail.com; b.rahal@crna.dz; benharrat.lyes@crtse.dz; serrarhacene@gmail.com; mokhtar.bousissa@univ-setif.dz; 


\section{Introduction}

Zinc Oxide $(\mathrm{ZnO})$ is is a multipurpose semiconductor with many uses such as ultra-capacitor electrode [?], spintronic devices [?], multigas sensing [? ? ? ? ], piezoelectric devices [? ], ultra-violet LEDs [? ], detectors [? ] as well as waveguides [? ? ? ]. In its thin film form, $\mathrm{ZnO}$ has a large adaptation to several deposition methods such as chemical vapor deposition [? ], pulsed laser deposition [?], spray pyrolysis [?], dip-coating [?] and electrochemical deposition [? ]. ZnO has very interesting characteristics for application in electronics and optoelectronics devices, especially its exciton binding energy of $60 \mathrm{meV}$ at $300 \mathrm{~K}$, a wide direct band gap of $3.37 \mathrm{eV}[?]$. In addition to an ordinary and extraordinary refractive indexes of $n_{e}=2.006$ and $n_{o}=1.990$ respectively [?]. To modify its electrical properties, $\mathrm{ZnO}$ was doped with Group III elements such as $\mathrm{Al}, \mathrm{Ga}$ and $\mathrm{In}$ which acted as donor dopants to reinforce its $n$-type electrical nature and group V elements such as N, P, As and Sb which acted as acceptor dopants which changed $\mathrm{ZnO}$ to be a $p$-type semiconductor [? ]. Controlling the refractive index of $\mathrm{ZnO}$ thin films was achieved by several ways including thermal annealing [? ] and doping with In [? ], Te, $\mathrm{N}$ [? ] and $\mathrm{Mg}$ [?]. However, the effect of dopants on the optical and electrical properties of $\mathrm{ZnO}$ is still not well understood.

Tailoring $\mathrm{ZnO}$ optical and electrical properties via dopants while maintaining high quality films especially using spray pyrolysis is very attractive to both scientists and technology developers as it offers a control over several experimental parameters, it is cheap, uncomplicated and environmentally friendly. Wurtzite $\mathrm{Mg}_{\mathrm{x}} \mathrm{Zn}_{1-\mathrm{x}} \mathrm{O}$ alloy is very interesting due to the high solubility of $\mathrm{Mg}$ in the $\mathrm{ZnO}$ wurtzite matrix (up to 30\%) [? ]. Moreover, it offers control over a range of optical and electrical properties of $\mathrm{ZnO}$ such as widening of the optical gap energy up to $0.85 \mathrm{eV}$ [? ], consequently, it can be used for multiple purposes such as a top layer in $\mathrm{Mg}_{\mathrm{x}} \mathrm{Zn}_{1-\mathrm{x}} \mathrm{O} / \mathrm{ZnO}$ multilayer UV photodetector [?] and high mobility $\mathrm{MgZnO} / \mathrm{ZnO}$ thin film transistor [?] to name few. Concerning the waveguiding properties, little attention has been paid to wurtzite $\mathrm{Mg}_{\mathrm{x}} \mathrm{Zn}_{1-\mathrm{x}} \mathrm{O}$ as a waveguide, however, $\mathrm{Mg}_{\mathrm{x}} \mathrm{Zn}_{1-\mathrm{x}} \mathrm{O}$ was used as a buffer layer for $\mathrm{ZnO}$ waveguide thin film [? ]. In an other work, a potential use of $\mathrm{Mg}_{\mathrm{x}} \mathrm{Zn}_{1-\mathrm{x}} \mathrm{O}$ cubic rocksalt-type phase as a wave guide was reported $\mathrm{Yu}$ et al. [? ]. Wurtzite $\mathrm{Mg}_{\mathrm{x}} \mathrm{Zn}_{1-\mathrm{x}} \mathrm{O}$ thin film alloy refractive index was previously studied but there is still work to be done, as there are opposite results regarding the birefringence which is found to be negative in some studies [? ? ] and positive in another study[?].

In this work, we engaged in the investigation of the relations between the refractive index, the optical gap energy and the charge carriers' density in addition to the birefringence of $\mathrm{Mg}_{\mathrm{x}} \mathrm{Zn}_{1-\mathrm{x}} \mathrm{O}$ thin films deposited by spray pyrolysis on glass substrate. 


\section{Results and Discussion}

\subsection{XRD analysis}

From Figure ??(a) we can see clearly that all films exhibit a crystalline hexagonal wurtzite structure (JCPDS card no. 00-036-1451) with the quasipredominance of (002) peak indicating the preferential growth of undoped and $\mathrm{Mg}$ doped $\mathrm{ZnO}$ thin films through the c-axis direction. However, weak intensity peaks of other crystallographic directions were observed in the following positions $31.96^{\circ}(100), 36.56^{\circ}(101), 47.87^{\circ}(102), 63.17^{\circ}(103)$ and $72.85^{\circ}(004)$. The peak (002) experienced a shift towards higher angles over Mg doping (Figure ??(b)) which was reported by a number of authors [? ? ?] and it is due to the difference in the ionic radius between $\mathrm{Mg}^{+2}(0.57 \AA)$ and $\mathrm{Zn}^{+2}(0.60 \AA)$ [? ]. This difference is directly related to the compression strain on the main axes of the wurtzite structure $a$ and $c$. Previously, Chang et al. [? ] reported also similar compression strain in their sputtered $\mathrm{MgZnO}$ thin films which were interpreted by good substitution between $\mathrm{Mg}$ and $\mathrm{Zn}$ ions.

The grain size can be calculated by Debye-Scherrer formula [?]:

$$
D=\frac{K \lambda}{\beta \cos (\theta)}
$$

where $\lambda$ is the wavelength of the incident $\mathrm{X}$-ray, $\theta$ is the Bragg's angle, $\mathrm{K}$ is the shape factor ( 0.9 for gaussian fit) and $\beta$ is the Full Width at Half Maxima (FWHM) of the peaks. The crystallite size, lattice parameters and strain axes are tabulated in table ??. It should be noted that there was no significant change in the average crystallite size $\left(33.13 \mathrm{~nm}\right.$ for $\mathrm{Mg}_{0} \mathrm{Zn}_{1} \mathrm{O}$ film and an average of $33.03 \mathrm{~nm}$ for the $\mathrm{Mg}_{\mathrm{x}} \mathrm{Zn}_{1-\mathrm{x}} \mathrm{O}$ films) and the minus sign of the strain values $\left(\epsilon_{a}\right.$ and $\left.\epsilon_{c}\right)$ approves the compression nature of the strain. To calculate lattice parameter $c$ of the thin films we used the Bragg's law (with $\mathrm{n}=1$ ) and the $d$ spacing of wurtzite structure.

\subsection{UV-Vis measurements}

The transmittance of the thin films was slightly enhanced on average with the introduction of $\mathrm{Mg}$ in the visible region $(400-800 \mathrm{~nm}$ ). The limit of the absorption zone was shifted to smaller wavelengths which renders the thin films to be more dielectric as $\mathrm{Mg}$ doping is increased, this effect is directly related to the blue shift of the optical band gap and it was approximated for each film using the Tauc's plot:

$$
\alpha h \nu=A\left(h \nu-E_{g}\right)^{n}
$$

where $h \nu$ is the photon energy, $E_{g}$ is the optical gap energy, A is constant and $n$ equals $\frac{1}{2}$ since $\mathrm{ZnO}$ has a direct band gap. The widening of the optical band gap could be ascribed to the difference in electronegativity between $\mathrm{Zn}^{+2}$ and $\mathrm{Mg}^{+2}$ ions [? ? ? ]. In similar study, Al-Ghamdi [?] reported this correlation 
between the optical band gap energy and the electronegativity in his work about amorphous $\mathrm{Se}_{96-x} \mathrm{Te}_{4} \mathrm{Ag}_{\mathrm{x}}$ thin films.

In fact, it should be noted that both the electronegativity and electron affinity are directly related [? ]. In this way Figure ?? presents the calculated optical band gap and the electron affinity versus $\mathrm{Mg}$ doping. The electron affinity $(e \chi)$ was quantitatively calculated using Vegard's law [? ]:

$$
e \chi\left(M g_{x} Z n_{1-x} O\right)=e \chi(Z n O)-(e \chi(Z n O)-e \chi(M g O)) x
$$

e $\chi(Z n O), e \chi(M g O)$ have the value of $4.5 \mathrm{eV}[?]$ and $0.85 \mathrm{eV}[?]$ for the electron affinity of $\mathrm{ZnO}$ and $\mathrm{MgO}$ respectively. Previously, iskenderoglu et al. [? ] approved experimentally by UPS technique the inverse relation between the optical gap energy and the electron affinity of sprayed $\mathrm{MgZnO}$ alloy thin film, with $\mathrm{Mg}$ doping ranging from 0 to $15 \%$.

\subsection{Photoluminescence}

The room temperature photoluminescence spectra are shown in Figure ??. The undoped thin film had four peaks at $381(3.25 \mathrm{eV}), 416(2.98 \mathrm{eV}), 441$ $(2.81 \mathrm{eV})$ and $505 \mathrm{~nm}(2.46 \mathrm{eV})$ which were explained by: the emission corresponding to excitons recombination, zinc interstitial $\left(\mathrm{Zn}_{\mathrm{i}}\right)$, oxygen vacancies $\left(\mathrm{V}_{\mathrm{O}}\right)$ and donor $\mathrm{V}_{\mathrm{O}}$ - acceptor $\mathrm{V}_{\mathrm{Zn}}$ recombination respectively [? ? ]. The same peaks were observed also in $\mathrm{Mg}_{0.01} \mathrm{Zn}_{0.99} \mathrm{O}$ except a blue shift of the 380 peak to $381 \mathrm{~nm}(3.26 \mathrm{eV})$. The $\mathrm{Mg}_{0.03} \mathrm{Zn}_{0.97} \mathrm{O}$ thin film had three peaks 379 $(3.27 \mathrm{eV}), 416(2.81 \mathrm{eV})$ and $492 \mathrm{~nm}(2.52 \mathrm{eV})$ and they were attributed to excitons recombination, zinc interstitial $\left(\mathrm{Zn}_{\mathrm{i}}\right)[?]$ and oxygen vacancy $\left(\mathrm{V}_{\mathrm{O}}\right)$ [?] respectively. Finally the $\mathrm{Mg}_{0.05} \mathrm{Zn}_{0.95} \mathrm{O}$ thin film exhibited two peaks at $378(3.28 \mathrm{eV})$ and $503 \mathrm{~nm}(2.47 \mathrm{eV})$ and they were manifestations of excitons and donor $\mathrm{V}_{\mathrm{O}}$ - acceptor $\mathrm{V}_{\mathrm{Zn}}$ recombinations [? ? ]. The blue shift of the near band edge emission from the PL peaks was in consistency with the UV visible calculations of the optical band gap, however, it was at a lower rate which was explained by stokes shift [?].

\subsection{Electrical measurements}

Figure ?? demonstrates the near isotropic electric transportation of the deposited films which could be attributed to the fact that the films have the predominant orientation (002) of the wurtzite structure [?].

The free charge carriers' density decreased from $3.146 \times 10^{18}$ for the undoped film to $9.273 \times 10^{13} \mathrm{~cm}^{-3}$ for $\mathrm{Mg}_{0.05} \mathrm{Zn}_{0.95} \mathrm{O}$ film. In parallel, the resistivity increased from 109 to $1268 \Omega \mathrm{cm}$ and the mobility increased from 0.01821 to $53.08 \mathrm{~cm}^{2} /$ (V.s). The decreased charge carriers' density could be attributed to the fact that the conduction band $(\mathrm{CB})$ of pure $\mathrm{ZnO}$ consists mainly of $\mathrm{O}_{2 \mathrm{p}}$ and $\mathrm{Zn}_{4 \mathrm{~s}}$ states [? ? ], so the introduction of $\mathrm{Mg}$ in $\mathrm{ZnO}$ thin films will reduce the $\mathrm{Zn}_{4 \mathrm{~s}}$ state and introduce $\mathrm{Mg}_{3 \mathrm{p}}$ state which has high energy relative to the $\mathrm{Zn}_{4 \mathrm{~s}}$ [? ? ]. Moreover, the widening in the optical bang gap energy discussed 
previously, could also influence the free charge carriers' density since the electrons passing from the valance band must requires higher energy to access the conduction band.

\subsection{Surface morphology}

Figure ?? shows the morphology of undoped and 5 at. \% doped $\mathrm{ZnO}$ thin films. The undoped (Figure ??(a)) thin film shows a dense surface with granular mixture of small grains and large aggregates. The size of the small grains varies from $\sim 20$ to $80 \mathrm{~nm}$ and that of the aggregates reaches $\sim 200-300 \mathrm{~nm}$. From the doped sample (Figure ??(b)), it is evident that magnesium has a tendency to promote the phenomenon of coalescence. This doped film shows a less dense and relatively homogeneous morphology with large aggregates whose size varies from $\sim 200$ to $500 \mathrm{~nm}$.

No cracks nor empty holes were observed on the surface of the films, revealing the high quality of our films.

\subsection{M-lines measurements}

The M-lines measurements demonstrated the guiding modes present in the films. All films had four guiding modes $\left(\mathrm{TE}_{0}, \mathrm{TE}_{1}, \mathrm{TM}_{0}\right.$, and $\left.\mathrm{TM}_{1}\right)$ two for each optical polarization (Transverse Electric mode (TE) and Transverse Magnetic mode (TM)) as illustrated in Figure ??. Using the dispersion equations for TE and TM polarizations, the optogeometric parameters can be calculated [? ? ? ]. The effective indices, the films thicknesses and the birefringence values are presented in Table ??.

Figure ?? illustrate the variation of $\mathrm{n}_{\mathrm{TE}}, \mathrm{n}_{\mathrm{TM}}$, optical gap energy and free charge carriers' density as a function of the $\mathrm{Mg}$ concentration. The slight difference between $n_{T M}$ and $n_{T E}$ confirmed the birefringence behavior of our films. This made the guided waves traveling during the TE mode in the plane perpendicular to the $c$-axis of the wurtzite structure submit to an ordinary refractive index $\left(\mathrm{n}_{\mathrm{TE}}\right)$ and during the TM mode to an extraordinary one $\left(\mathrm{n}_{\mathrm{TM}}\right)$ [?]. Both $\mathrm{n}_{\mathrm{TE}}$ and $\mathrm{n}_{\mathrm{TM}}$ were found to decreased over Mg doping. This behavior seems to be in good agreement with the broadening of the optical band gap and the depletion of the conduction band free charge carriers' (Figure ??) [? ]. The birefringence was measured to be positive for all films which is a good indication for the unchanging orientations of the bonds $\mathrm{Zn}-\mathrm{O}$ with the replacement of $\mathrm{Zn}$ by $\mathrm{Mg}$ [? ? ].

The inverse relation between the optical gap energy, the resistivity and the refractive index as $\mathrm{Mg}$ content increased in the $\mathrm{ZnO}$ thin film was also observed by Kaushal et al. [? ]. The same fact has been reported by Teng et al. [? ] for $\mathrm{Mg}$-doped $\mathrm{ZnO}$ thin films prepared by pulsed laser deposition. In similar study, Sorar et al. [?] found that the ordinary refractive index generally decreases with the increase of the $\mathrm{Si}$ doping in $\mathrm{ZnO}$ thin films prepared by sol-gel and annealed at $350{ }^{\circ} \mathrm{C}$ and $550{ }^{\circ} \mathrm{C}$ whereas their optical band gap energy was found to be blue shifted. 


\section{Tables}

\section{Figures}
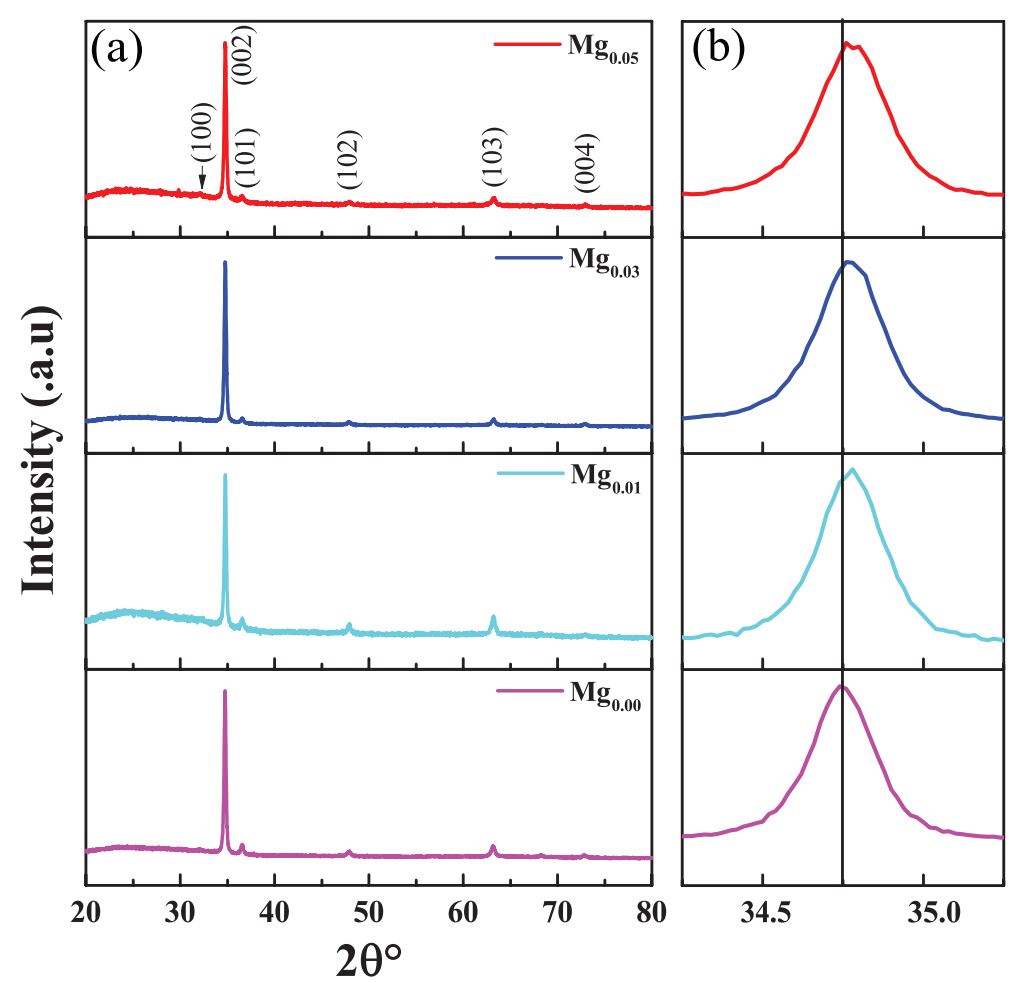

Fig. 1 (a) XRD spectra of undoped and $\mathrm{Mg}$ doped $\mathrm{ZnO}$ thin films, (b) an emphasis of the (002) peak showing a shift towards higher angles for the doped thin films.

\section{Methods}

The sprayed solution for the undoped $\mathrm{ZnO}$ thin films was prepared by dissolving the proper amount of dihydrate zinc acetate $\left[\mathrm{Zn}\left(\mathrm{CH}_{3} \mathrm{CO}_{2}\right)_{2} \cdot 2 \mathrm{H}_{2} \mathrm{O}\right]$ in $99.98 \%$ pure methanol to obtain $0.1 \mathrm{M}$ solution that was submitted to a constant stirring at $60{ }^{\circ} \mathrm{C}$ for $45 \mathrm{~min}$ on a magnetic stirrer. Concerning the sprayed solution of the $\mathrm{Mg}$ doped $\mathrm{ZnO}$ thin films, we maintained the same parameters with the use of magnesium chloride $\left[\mathrm{Mg}\left(\mathrm{CH}_{3} \mathrm{CO}_{2}\right)_{2} \cdot 4 \mathrm{H}_{2} \mathrm{O}\right]$ as $\mathrm{Mg}$ precursor and each time the proper amount was added to $0.1 \mathrm{M}$ methanol solutions of $\mathrm{Zn}\left(\mathrm{CH}_{3} \mathrm{CO}_{2}\right)_{2} \cdot 2 \mathrm{H}_{2} \mathrm{O}$ to produce the following contents of zinc and magnesium: $\mathrm{Mg}_{\mathrm{x}} \mathrm{Zn}_{1-\mathrm{x}} \mathrm{O}$ with $\mathrm{x}$ equals $0.01,0.03$ and 0.05 .

An ordinary glass substrate were ultra-sonically cleaned in a 1:1 mixture of acetone and ethanol for $15 \mathrm{~min}$ and left to dry in air. The films were deposited 
Table 1 The information obtained and calculated from the XRD spectra.

\begin{tabular}{|c|c|c|c|c|c|c|c|}
\hline Sample & $2 \theta$ (degree $)$ & $d$ spacing $(\AA)$ & Crystallite size (nm) & $a(\AA)$ & $c(\AA)$ & $\epsilon_{a}\left(10^{-3}\right)$ & $\epsilon_{c}\left(10^{-3}\right)$ \\
\hline $\mathrm{Mg}_{0.00} \mathrm{Zn}_{1.00} \mathrm{O}$ & 34.75 & 2.580 & 33.13 & 3.2306 & 5.1592 & -3.4241 & -5.4746 \\
\hline $\mathrm{Mg}_{0.01} \mathrm{Zn}_{0.99} \mathrm{O}$ & 34.77 & 2.455 & 31.26 & 3.2240 & 5.1560 & -5.4601 & -6.0915 \\
\hline $\mathrm{Mg}_{0.03} \mathrm{Zn}_{0.97} \mathrm{O}$ & 34.77 & 2.456 & 31.30 & 3.2256 & 5.1560 & -4.9665 & -6.0915 \\
\hline $\mathrm{Mg}_{0.05} \mathrm{Zn}_{0.95} \mathrm{O}$ & 34.78 & 2.577 & 35.83 & 3.2298 & 5.1547 & -3.6709 & -6.3421 \\
\hline
\end{tabular}


Table 2 Optogeometric Properties of the deposited thin films.

\begin{tabular}{|c|c|c|c|c|c|c|c|c|c|}
\hline \multirow{2}{*}{ Sample } & \multicolumn{4}{|c|}{ Effective index $\pm 10^{-4}$} & \multicolumn{2}{|c|}{ Refractive index $10^{-4}$} & \multirow{2}{*}{$\begin{array}{c}\text { Thickness TE } \\
\quad \pm 0.1 \mathrm{~nm}\end{array}$} & \multirow{2}{*}{$\begin{array}{c}\text { Thickness TM } \\
\quad \pm 0.1 \mathrm{~nm}\end{array}$} & \multirow{2}{*}{$\begin{array}{l}\text { Birefringence } \\
\left(\mathrm{n}_{\mathrm{TM}}-\mathrm{n}_{\mathrm{TE}}\right)\end{array}$} \\
\hline & $\mathrm{TE}_{0}$ & $\mathrm{TE}_{1}$ & $\mathrm{TM}_{0}$ & $\mathrm{TM}_{1}$ & $\mathrm{n}_{\mathrm{TE}}$ & $\mathrm{n}_{\mathrm{TM}}$ & & & \\
\hline $\mathrm{Mg}_{0.00} \mathrm{Zn}_{1} .00 \mathrm{O}$ & 1.8923 & 1.6565 & 1.8793 & 1.6033 & 1.9699 & 1.9761 & 436.1 & 452.1 & 0.0062 \\
\hline $\mathrm{Mg}_{0.01} \mathrm{Zn}_{0.99} \mathrm{O}$ & 1.8758 & 1.5994 & 1.8539 & 1.5486 & 1.9680 & 1.9682 & 347.4 & 382.6 & 0.0002 \\
\hline $\mathrm{Mg}_{0.03} \mathrm{Zn}_{0.97} \mathrm{O}$ & 1.8738 & 1.6203 & 1.8581 & 1.5647 & 1.9580 & 1.9652 & 413.1 & 426.3 & 0.0072 \\
\hline $\mathrm{Mg}_{0.05} \mathrm{Zn}_{0.95} \mathrm{O}$ & 1.8451 & 1.5981 & 1.8278 & 1.5494 & 1.9278 & 1.9314 & 417.7 & 433.7 & 0.0036 \\
\hline
\end{tabular}




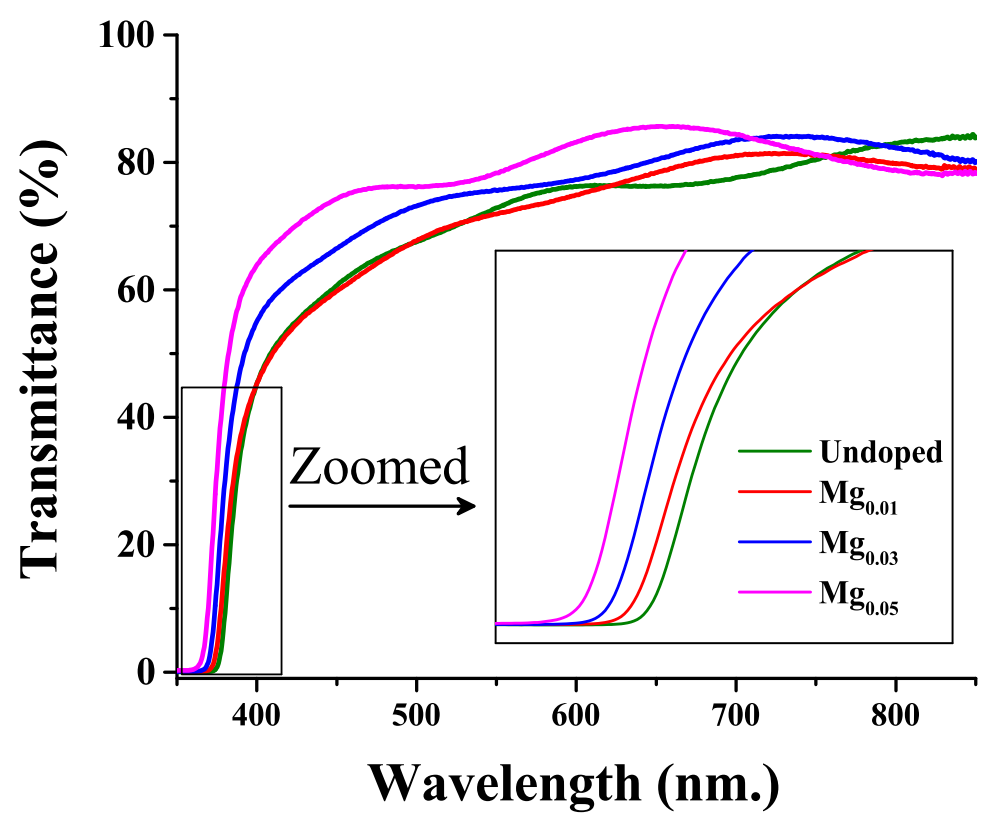

Fig. 2 Transmittance spectra of pure and doped $\mathrm{ZnO}$ thin films zoomed in the absorption region.

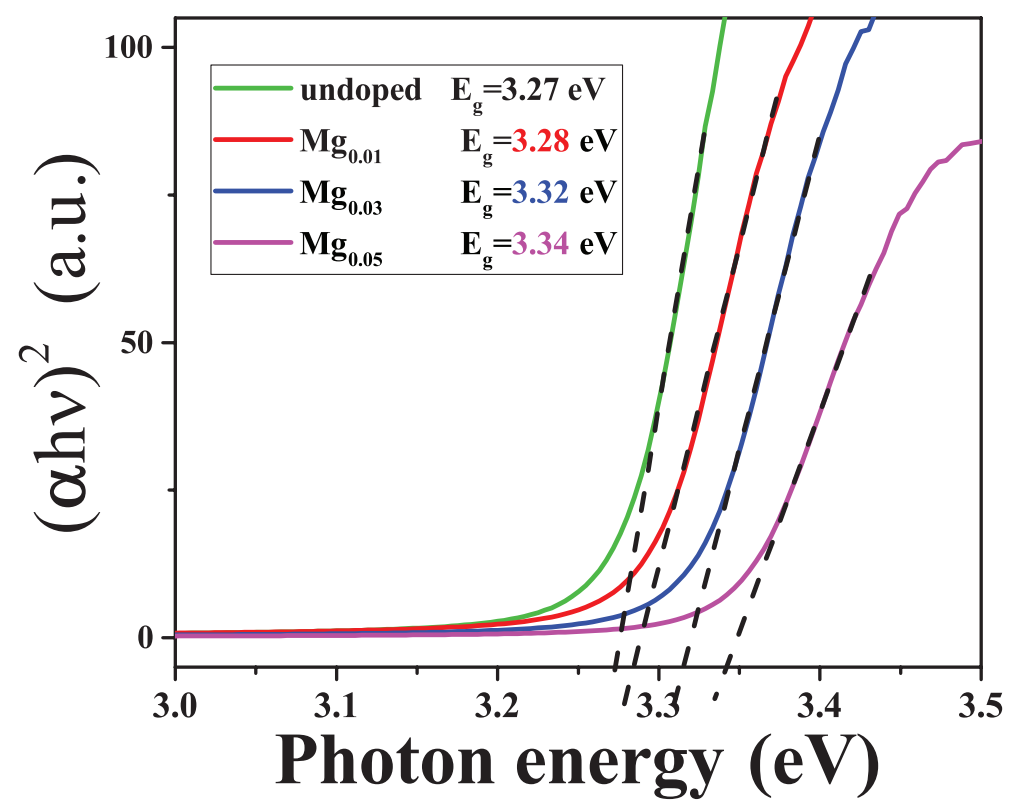

Fig. 3 Tauc's plot for the undoped and doped $\mathrm{ZnO}$ thin films. 


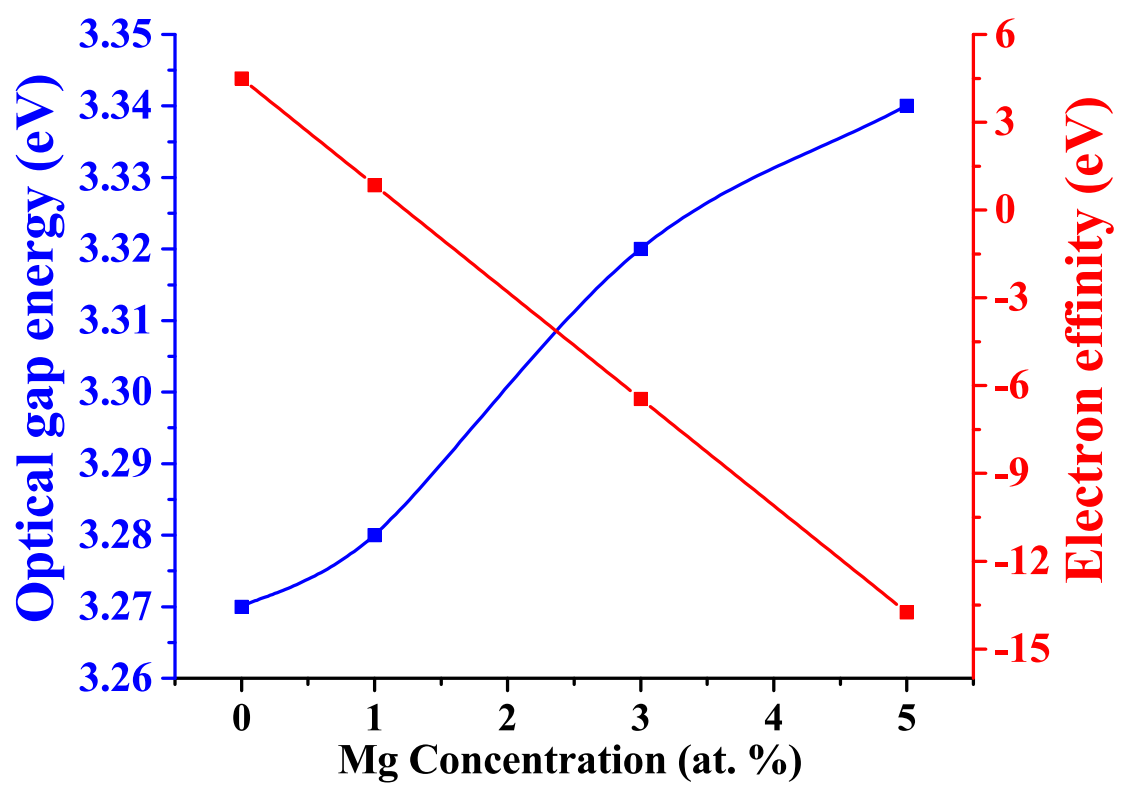

Fig. 4 The evolution of the optical band gap energy and the electron affinity of $\mathrm{Mg}_{\mathrm{x}} \mathrm{Zn}_{1-\mathrm{x}} \mathrm{O}$ thin films as a function of $\mathrm{Mg}$ concentration.
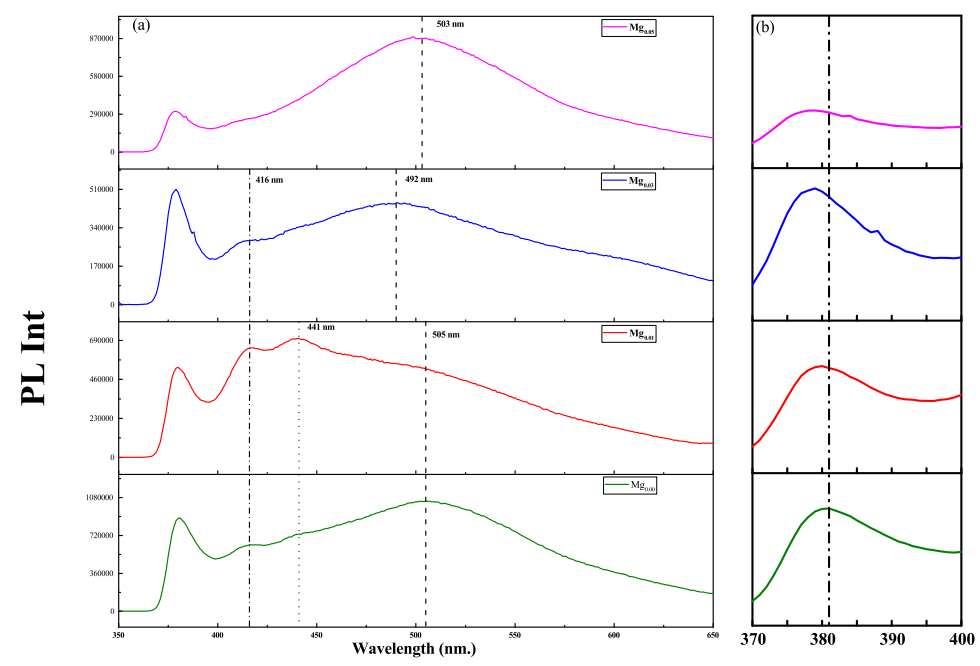

Fig. 5 (a) Room temperature photoluminescence spectra, (b) an emphasis of the excitons recombination peaks. 
Optoelectronic and birefringence properties of weakly $\mathrm{Mg}$ doped $\mathrm{ZnO}$ thin films prepared by s
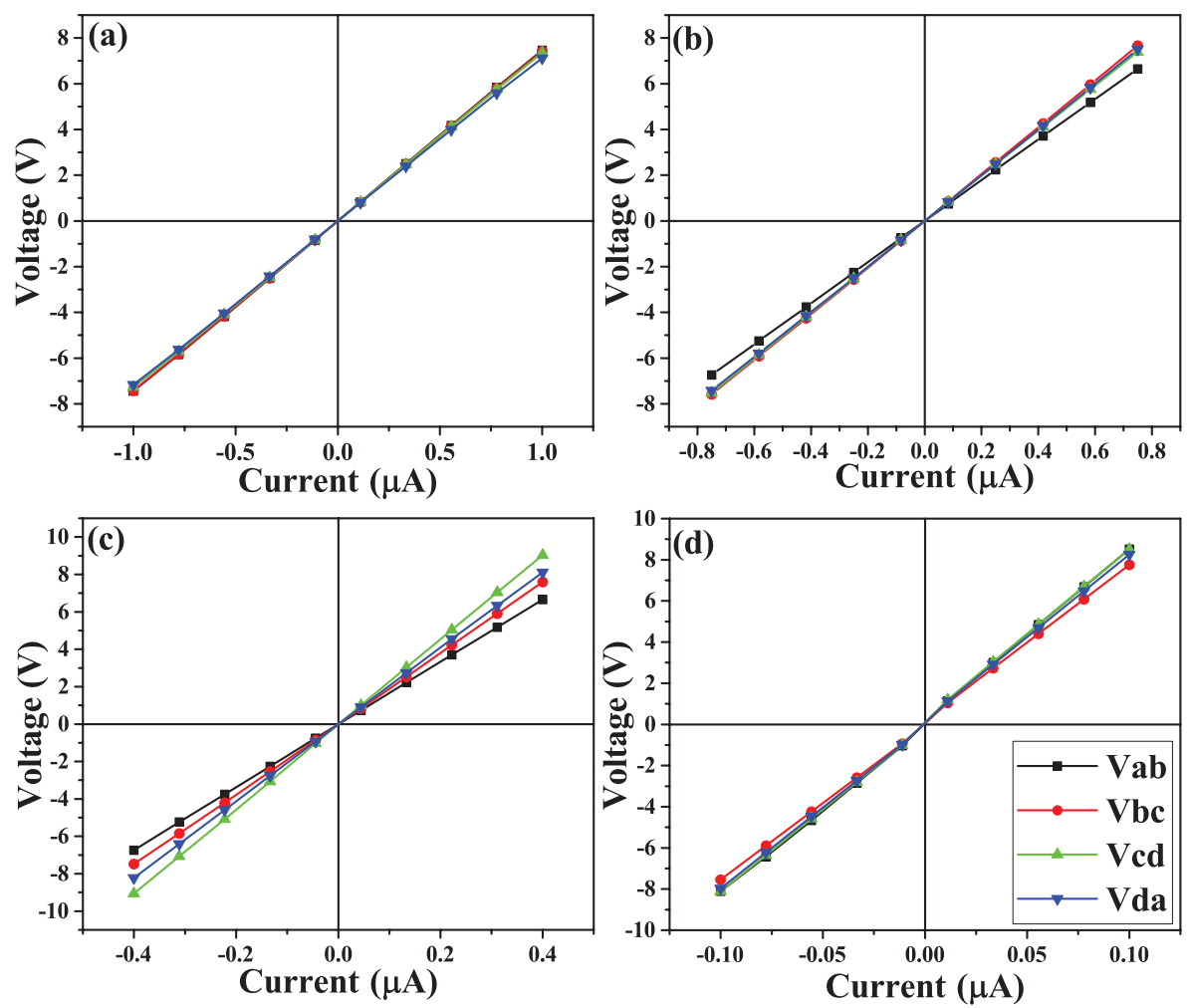

Fig. 6 I-V measurements for the four thin films: (a) undoped $\mathrm{ZnO}$, (b) $\mathrm{Mg}_{0.01} \mathrm{Zn}_{0.99} \mathrm{O}$, (c) $\mathrm{Mg}_{0.03} \mathrm{Zn}_{0.97} \mathrm{O}$ and $(\mathrm{d}) \mathrm{Mg}_{0.05} \mathrm{Zn}_{0.95} \mathrm{O}$.

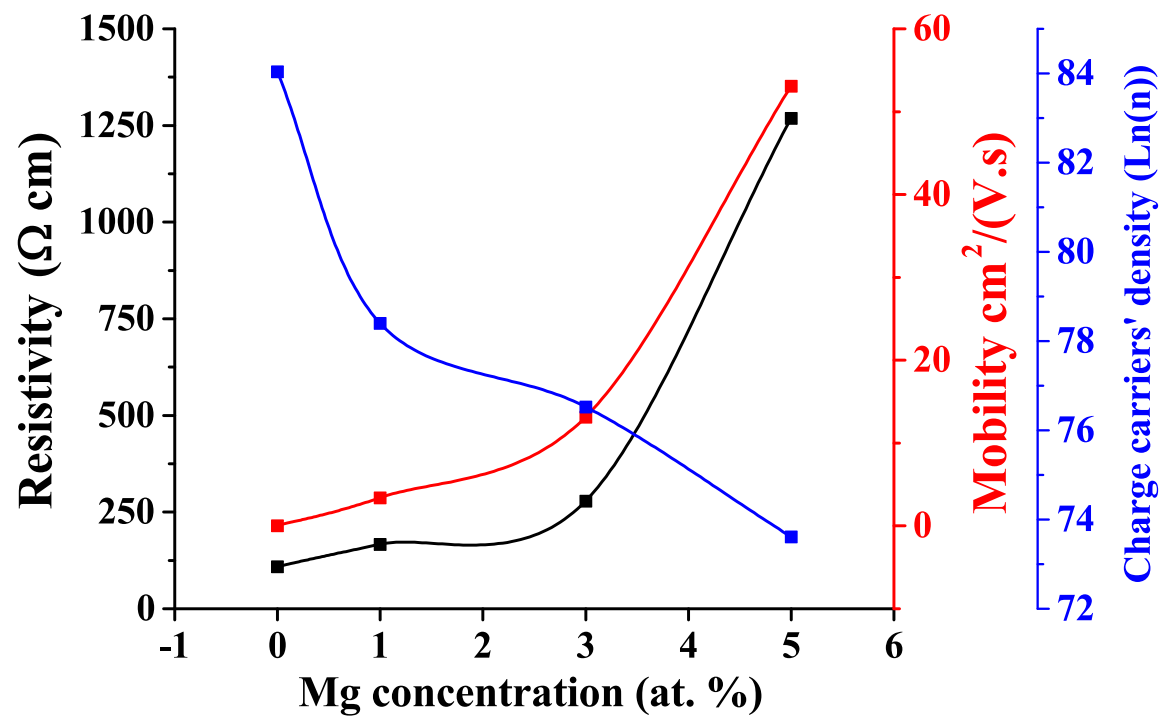

Fig. 7 Resistivity $(\rho)$ and charge carriers $(n)$ as a function of $\mathrm{Mg}$ concentration. 
using spray pyrolysis system. The deposition temperature was $450{ }^{\circ} \mathrm{C}$.

In order to characterize our thin films, multiple techniques were used: Philips PANalytical X'Pert Pro diffractometer with a wave length of $1.5406 \AA$, environmental scanning electron microscope Philips XL30 ESEM FEG and for the electrical properties Ecopia HMS-3000 hall effect measurement system, finally for the optical measurements, Metricon 2010/M Prism (rutile $\mathrm{TiO}_{2}: \mathrm{n}_{\mathrm{e}}=2,8639$ and $\mathrm{n}_{\mathrm{o}}=2.5822$ at $632,8 \mathrm{~nm}$ with an apical angle of $44,60^{\circ}$ ) Coupler was used to couple $632.8 \mathrm{~nm}$ HeNe laser light into air $/ \mathrm{Mg}_{\mathrm{x}} \mathrm{Zn}_{1-\mathrm{x}} \mathrm{O} /$ glass waveguide and Shimadzu UV-3101PC Spectrophotometer.

\section{Conclusion}

$\mathrm{Mg}$ doped $\mathrm{ZnO}$ thin films were successfully deposited on glass substrate via spray pyrolysis at $450{ }^{\circ} \mathrm{C}$. The XRD characterization showed highly $c$ oriented thin films with a decrease in $a$ and $c$ as the $\mathrm{Mg}$ concentration increased in the thin films. The undoped thin film had a multisize grain distribution meanwhile the $\mathrm{Mg}_{0.05} \mathrm{Zn}_{0.95} \mathrm{O}$ had a more homogeneous grain distribution. $\mathrm{Mg}$ doping in the $\mathrm{ZnO}$ films led to a blue shift of the optical band gap energy and a depletion of the conduction band due to the drop in free carriers' density that had a direct effect on the ordinary and the extraordinary refractive indexes that were found to decrease. The birefringence of a crystal depends on multiple factors such as strain, defects charge carriers' density, bounds orientations and so on, therefore it will change from papers to papers with the change of deposition method especially.

\section{Declarations}

- Funding: Not applicable

- Conflict of interest/Competing interests: The authors declare that they have no conflict of interest.

- Ethics approval: Not applicable

- Consent to participate: Not applicable

- Consent for publication: Not applicable

- Availability of data and materials: Not applicable

- Code availability: Not applicable

- Authors' contributions: Not applicable

\section{References}

[1] Lakshmi, K., Revathi, S.: Rice-like zno architecture: An eminent electrode material for high-performance ultracapacitor application. Journal of Inorganic and Organometallic Polymers and Materials 31(5), 1992-2002 (2021). https://doi.org/10.1007/s10904-021-01922-5

[2] Pearton, S., Norton, D., Heo, Y., Tien, L.-C., Ivill, M., Li, Y., Kang, B., Ren, F., Kelly, J., Hebard, A.: Zno spintronics and nanowire devices. 
Optoelectronic and birefringence properties of weakly $\mathrm{Mg}$ doped $\mathrm{ZnO}$ thin films prepared by

Journal of Electronic Materials 35, 862-868 (2006). https://doi.org/10. $1007 / \mathrm{BF} 02692541$

[3] Hosseinnejad, M.T., Shirazi, M., Ghoranneviss, M., Hantehzadeh, M.R., Darabi, E.: Preparation of nanostructured zno thin films using magnetron sputtering for the gas sensors applications. Journal of Inorganic and Organometallic Polymers and Materials 26(2), 405-412 (2016). https: //doi.org/10.1007/s10904-015-0324-0

[4] Hjiri, M., Bahanan, F., Aida, M., El Mir, L., Neri, G.: High performance co gas sensor based on zno nanoparticles. Journal of Inorganic and Organometallic Polymers and Materials 30(10), 4063-4071 (2020). https://doi.org/10.1007/s10904-020-01553-2

[5] Blauw, M., Dam, V.A., Crego-Calama, M., Brongersma, S., Musschoot, J., Detavernier, C.: Oxygen sensing with zno thin films. Proceedings of IEEE Sensors 28-31, 1416-1419 (2011). https://doi.org/10.1109/ ICSENS.2011.6127128

[6] Patil, V.L., Vanalakar, S.A., Patil, P.S., Kim, J.H.: Fabrication of nanostructured zno thin films based no2 gas sensor via silar technique. Sensors and Actuators B: Chemical 239, 1185-1193 (2017). https://doi.org/10. 1016/j.snb.2016.08.130

[7] Polewczyk, V., Maffei, R., Vinai, G., Cicero, M., Prato, S., Capaldo, P., Zilio, S., Bona, A., Paolicelli, G., Mescola, A., D’Addato, S., Torelli, P., Benedetti, S.: Zno thin films growth optimization for piezoelectric application. Sensors 21, 6114 (2021). https://doi.org/10.3390/s21186114

[8] Sandeep, K.M., Bhat, S., Dharmaprakash, S.M.: Structural, optical, and led characteristics of zno and al doped zno thin films. Journal of Physics and Chemistry of Solids 104, 36-44 (2017). https://doi.org/10.1016/j. jpcs.2017.01.003

[9] Shaikh, S., Ganbavle, V., Inamdar, S., Rajpure, K.: Multifunctional zinc oxide thin films for high performance uv photodetector and nitrogen dioxide gas sensor. RSC Adv. 6 (2016). https://doi.org/10.1039/ C6RA01750A

[10] Kamauchi, M., Shiosaki, T., Kawabata, A.: Channel optical waveguides of zno thin films. In: [Proceedings] 1990 IEEE 7th International Symposium on Applications of Ferroelectrics, pp. 733-736 (1990). https://doi.org/10. 1109/ISAF.1990.200361

[11] Yu, S.F., Yuen, C., Lau, S.P., Fan, W.J.: Design and fabrication of zinc oxide thin-film ridge waveguides on silicon substrate with ultraviolet amplified spontaneous emission. IEEE Journal of Quantum Electronics 
40(4), 406-412 (2004). https://doi.org/10.1109/JQE.2004.825212

[12] Teraoka, E., Kita, T., Tsukazaki, A., Kawasaki, M., Yamada, H.: Fabrication of zno channel waveguides for nonlinear optical applications. Proceedings of SPIE - The International Society for Optical Engineering 7940 (2011). https://doi.org/10.1117/12.874439

[13] Chen, Z., Shum, K., Salagaj, T., Zhang, W., Strobl, K.: Zno thin films synthesized by chemical vapor deposition, pp. 1-6 (2010). https://doi. org/10.1109/LISAT.2010.5478331

[14] Shan, F.K., Shin, B.C., Jang, S.W., Yu, Y.S.: Substrate effects of zno thin films prepared by pld technique. Journal of the European Ceramic Society 24(6), 1015-1018 (2004). https://doi.org/10.1016/S0955-2219(03) 00397-2. Electroceramics VIII

[15] Lehraki, N., Aida, M.S., Abed, S., Attaf, N., Attaf, A., Poulain, M.: Zno thin films deposition by spray pyrolysis: Influence of precursor solution properties. Current Applied Physics 12(5), 1283-1287 (2012). https:// doi.org/10.1016/j.cap.2012.03.012

[16] Rahal, B., Boudine, B., Larbah, Y., Siad, M., Souami, N.: Influence of low cd-doping concentration (0.5 and 3 wt.\%) and different substrate types (glass and silicon) on the properties of dip-coated nanostructured zno semiconductors thin films. Journal of Inorganic and Organometallic Polymers and Materials, 1-17 (2021). https://doi.org/10. 1007/s10904-021-02024-y

[17] Hamidi, A.S., Abidin, M.S.Z.: Electrochemical deposition of zinc oxide thin film using two-terminal setup. In: 2017 IEEE Regional Symposium on Micro and Nanoelectronics (RSM), pp. 34-37 (2017). https://doi.org/ 10.1109/RSM.2017.8069136

[18] Ellmer, K., Klein, A., Rech, B. (eds.): Transparent Conductive Zinc Oxide: Basics and Applications in Thin Film Solar Cells. Springer series in materials science, vol. 104. Springer, Berlin (2008). OCLC: ocn181423059

[19] Mehan, N., Tomar, M., Gupta, V., Mansingh, A.: Optical waveguiding and birefringence properties of sputtered zinc oxide (zno) thin films on glass. Optical Materials 27(2), 241-248 (2004). https://doi.org/10.1016/ j.optmat.2004.03.005

[20] Jagadish, C., Pearton, S.J.: Zinc Oxide Bulk, Thin Films and Nanostructures: Processing, Properties, and Applications vol. 7. Elsevier, ??? (2011)

[21] Huang, B., Li, J., Wu, Y.-b., Guo, D.-h., Wu, S.-t.: Optical constants of 
Optoelectronic and birefringence properties of weakly $\mathrm{Mg}$ doped $\mathrm{ZnO}$ thin films prepared by s

transparent zno films by rf magnetron sputtering. Materials Letters 62(8), 1316-1318 (2008). https://doi.org/10.1016/j.matlet.2007.08.043

[22] Xie, G.C., Fanga, L., Peng, L.P., Liu, G.B., Ruan, H.B., Wu, F., Kong, C.Y.: Effect of In-doping on the Optical Constants of ZnO Thin Films. Physics Procedia 32, 651-657 (2012). https://doi.org/10.1016/j.phpro. 2012.03.614. Accessed 2021-07-23

[23] Cai, A.L., Muth, J.F., Porter, H.L., Kvit, A., Narayan, J.: The refractive index and other properties of doped zno films. MRS Proceedings 764, 3-21 (2003). https://doi.org/10.1557/PROC-764-C3.21

[24] Teng, C., Muth, J., Ozgur, U., Bergmann, M., Everitt, H., Sharma, A., Jin, C., Narayan, J.: Refractive indices and absorption coefficients of mgxzn1-xo alloys. Applied Physics Letters 76, 979-981 (2000). https: //doi.org/10.1063/1.125912

[25] iskenderoglu, D., Kasapoglu, A., Gür, E.: Valance band properties of mgzno thin films with increasing mg content; phase separation effects. Materials Research Express 6 (2018). https://doi.org/10.1088/2053-1591/ aaf45e

[26] Özgür, ., Alivov, Y.I., Liu, C., Teke, A., Reshchikov, M.A., Doğan, S., Avrutin, V., Cho, S.-J., Morkoç, H.: A comprehensive review of zno materials and devices. Journal of Applied Physics 98(4), 041301 (2005) https://arxiv.org/abs/https://doi.org/10.1063/1.1992666. https: //doi.org/10.1063/1.1992666

[27] Rana, V.S., Rajput, J.K., Pathak, T.K., Purohit, L.P.: Multilayer mgzno/zno thin films for uv photodetectors. Journal of Alloys and Compounds 764, 724-729 (2018). https://doi.org/10.1016/j.jallcom.2018.06. 139

[28] Yue, D., Guo, S., Han, S., Cao, P., Zeng, Y., Xu, W., Fang, M., Liu, W., Zhu, D., Lu, Y., Qian, Y.: Facile fabrication of mgzno/zno composites for high performance thin film transistor. Journal of Alloys and Compounds 873, 159840 (2021). https://doi.org/10.1016/j.jallcom.2021.159840

[29] Jia, C.-L., Wang, K.-M., Wang, X.-L., Zhang, X.-J., Lu, F.: Formation of c-axis oriented zno optical waveguides by radio-frequency magnetron sputtering. Optics express 13, 5093-9 (2005). https://doi.org/10.1364/ OPEX.13.005093

[30] Yu, P., Wu, H.Z., Xu, T.N., Qiu, D.J., Hu, G.J., Dai, N.: Cubic phase mgxzn1-xo thin films for optical waveguides. Journal of Crystal Growth 310(2), 336-340 (2008). https://doi.org/10.1016/j.jcrysgro.2007.10.028 
[31] Morkoç, H., Özgür, m.: Zinc Oxide: Fundamentals, Materials and Device Technology, 1st edn. Wiley, ??? (2009). https://doi.org/10. 1002/9783527623945. https://onlinelibrary.wiley.com/doi/book/10.1002/ 9783527623945 Accessed 2021-07-26

[32] Khorramshahi, V., Karamdel, J., Yousefi, R.: Acetic acid sensing of Mg-doped $\mathrm{ZnO}$ thin films fabricated by the sol-gel method. Journal of Materials Science: Materials in Electronics 29(17), 14679-14688 (2018). https://doi.org/10.1007/s10854-018-9604-0. Accessed 2021-06-18

[33] Kim, T.H., Park, J.J., Nam, S.H., Park, H.S., Cheong, N.R., Song, J.K., Park, S.M.: Fabrication of Mg-doped $\mathrm{ZnO}$ thin films by laser ablation of Zn:Mg target. Applied Surface Science 255(10), 5264-5266 (2009). https: //doi.org/10.1016/j.apsusc.2008.07.105. Accessed 2021-06-18

[34] Shan, F.K., Kim, B.I., Liu, G.X., Liu, Z.F., Sohn, J.Y., Lee, W.J., Shin, B.C., Yu, Y.S.: Blueshift of near band edge emission in $\mathrm{Mg}$ doped $\mathrm{ZnO}$ thin films and aging. Journal of Applied Physics 95(9), 4772-4776 (2004). https://doi.org/10.1063/1.1690091. Accessed 2021-06-18

[35] Rouchdi, M., Salmani, E., Fares, B., Hassanain, N., Mzerd, A.: Synthesis and characteristics of $\mathrm{Mg}$ doped $\mathrm{ZnO}$ thin films: Experimental and abinitio study. Results in Physics 7, 620-627 (2017). https://doi.org/10. 1016/j.rinp.2017.01.023. Accessed 2021-06-18

[36] Chang, R.-C., Chu, S.-Y., Yeh, P.-W., Hong, C.-S., Kao, P.-C., Huang, Y.-J.: The influence of $\mathrm{Mg}$ doped $\mathrm{ZnO}$ thin films on the properties of Love wave sensors. Sensors and Actuators B: Chemical 132(1), 290-295 (2008). https://doi.org/10.1016/j.snb.2008.01.038. Accessed 2021-06-18

[37] Hussain, F., Imran, M., Khalil, R.M.A., Niaz, N.A., Rana, A.M., Sattar, M.A., Ismail, M., Majid, A., Kim, S., Iqbal, F., Javid, M.A., Saeed, S., Sattar, A.: An insight of $\mathrm{Mg}$ doped $\mathrm{ZnO}$ thin films: A comparative experimental and first-principle investigations. Physica E: Low-dimensional Systems and Nanostructures 115, 113658 (2020). https://doi.org/10. 1016/j.physe.2019.113658. Accessed 2021-06-18

[38] Huang, K., Tang, Z., Zhang, L., Yu, J., Lv, J., Liu, X., Liu, F.: Preparation and characterization of $\mathrm{Mg}$-doped $\mathrm{ZnO}$ thin films by sol-gel method. Applied Surface Science 258(8), 3710-3713 (2012). https://doi.org/10. 1016/j.apsusc.2011.12.011. Accessed 2021-06-18

[39] Agrawal, A., Dar, T.A., Sen, P., Phase, D.M.: Transport and magnetotransport study of $\mathrm{Mg}$ doped $\mathrm{ZnO}$ thin films. Journal of Applied Physics 115(14), 143701 (2014). https://doi.org/10.1063/1.4870864. Accessed 2021-06-18 
[40] Al-Ghamdi, A.A.: Optical band gap and optical constants in amorphous Se96-xTe4Agx thin films. Vacuum 80(5), 400-405 (2006). https://doi.org/ 10.1016/j.vacuum.2005.07.003. Accessed 2021-09-18

[41] Mulliken, R.S.: A New Electroaffinity Scale; Together with Data on Valence States and on Valence Ionization Potentials and Electron Affinities. The Journal of Chemical Physics 2(11), 782-793 (1934). https: //doi.org/10.1063/1.1749394. Accessed 2021-09-17

[42] Vegard, L.: Die konstitution der mischkristalle und die raumfüllung der atome. Zeitschrift für Physik 5(1), 17-26 (1921)

[43] Hussain, B., Aslam, A., Khan, T.M., Creighton, M., Zohuri, B.: Electron affinity and bandgap optimization of zinc oxide for improved performance of zno/si heterojunction solar cell using pc1d simulations. Electronics $\mathbf{8}(2), 238(2019)$

[44] Aboelfotoh, M.O., Lorenzen, J.A.: Influence of secondary-electron emission from mgo surfaces on voltage-breakdown curves in penning mixtures for insulated-electrode discharges. Journal of Applied Physics 48(11), 4754-4759 (1977) https://arxiv.org/abs/https://doi.org/ 10.1063/1.323490. https://doi.org/10.1063/1.323490

[45] Mishra, S., Srivastava, R., Prakash, S., Yadav, R., Panday, A.: Photoluminescence and photoconductive characteristics of hydrothermally synthesized zno nanoparticles. Opto-Electronics Review 18(4), 467-473 (2010)

[46] Chen, H., Ding, J., Guo, W., Chen, G., Ma, S.: Blue-green emission mechanism and spectral shift of al-doped zno films related to defect levels. RSC Adv. 3, 12327-12333 (2013). https://doi.org/10.1039/C3RA40750K

[47] Babu, K.S., Reddy, A.R., Sujatha, C., Reddy, K.V., Mallika, A.: Synthesis and optical characterization of porous zno. Journal of Advanced Ceramics 2(3), 260-265 (2013)

[48] Kim, T.H., Park, J.J., Nam, S.H., Park, H.S., Cheong, N.R., Song, J.K., Park, S.M.: Fabrication of mg-doped zno thin films by laser ablation of zn: Mg target. Applied Surface Science 255(10), 5264-5266 (2009)

[49] Oliveira, M., Castro, A., Marques, M., Rubio, A.: On the use of neumann's principle for the calculation of the polarizability tensor of nanostructures. Journal of nanoscience and nanotechnology 8, 3392-8 (2008). https://doi. org/10.1166/jnn.2008.142

[50] Hu, Y., Zeng, H., Du, J., Hu, Z., Zhang, S.: The structural, electrical and optical properties of mg-doped $\mathrm{ZnO}$ with different interstitial $\mathrm{mg}$ 
concentration. Materials Chemistry and Physics 182, 15-21 (2016). https: //doi.org/10.1016/j.matchemphys.2016.05.065. Accessed 2021-06-29

[51] Bustanafruz, F., Fazli, M., Mohammadizadeh, M.R., Jafar Tafreshi, M.: Optical and electronic properties of h-doped $\mathrm{ZnO}$. Optical and Quantum Electronics 48(5), 297 (2016). https://doi.org/10.1007/ s11082-016-0575-1. Accessed 2021-06-29

[52] Wang, J., Tu, Y., Yang, L., Tolner, H.: Theoretical investigation of the electronic structure and optical properties of zinc-doped magnesium oxide. Journal of Computational Electronics 15, 1521-1530 (2016). https://doi. org $/ 10.1007 /$ s10825-016-0906-2

[53] Zheng, W., Feng, Z.C., Chang, F.H., Lee, J.F., Zheng, R.S., Wuu, D.S., Liu, C.W.: Study of $\mathrm{Mg}_{\mathrm{x}} \mathrm{Zn}_{1-\mathrm{x}} \mathrm{O}$ Alloys $(0<\mathrm{x}<0.15)$ by X-Ray Absorption Spectroscopy. Advanced Materials Research 663, 361-365 (2013). https:// doi.org/10.4028/www.scientific.net/AMR.663.361. Accessed 2021-07-29

[54] Bouachiba, Y., Taabouche, A., Bouabellou, A., Hanini, F., Sedrati, C., Merabti, H.: Tio waveguides thin films prepared by sol-gel method on glass substrates with and without zno underlayer. Materials Science-Poland 38(3), 381-385 (2020). https://doi.org/10.2478/msp-2020-0043

[55] Medjaldi, F., Bouabellou, A., Bouachiba, Y., Taabouche, A., Bouatia, K., Serrar, H.: Study of $\mathrm{TiO} 2, \mathrm{SnO} 2$ and nanocomposites $\mathrm{TiO} 2 \mathrm{SnO} 2$ thin films prepared by sol-gel method: Successful elaboration of variable-refractive index systems $\mathbf{7}(1), 016439$ (2020). https://doi.org/10. 1088/2053-1591/ab6c0c

[56] Gharbi, B., Taabouche, A., Brella, M., Gheriani, R., Bouachiba, Y., Bouabellou, A., Hanini, F., Barouk, S.L., Serrar, H., Rahal, B.: Spray pyrolysis synthesized and zno-nio nanostructured thin films analysis with their nanocomposites for waveguiding applications. Semiconductors 55, 37-43 (2021)

[57] Feynman, R.P., Leighton, R.B., Sands, M.: The Feynman Lectures on Physics; New Millennium Ed. Basic Books, New York, NY (2010). Originally published 1963-1965. https://cds.cern.ch/record/1494701

[58] Weber, H.-J.: Anisotropic bond polarizabilities in birefringent crystals. Acta Crystallographica Section A 44(3), 320-326 (1988). https://doi.org/ 10.1107/S0108767387012492

[59] Lidin, S.: Mapping bond orientations with polarized x-rays. Science 344(6187), 969-970 (2014). https://doi.org/10.1126/science.1254902

[60] Kaushal, A., Kaur, D.: Effect of mg content on structural, electrical and 
Optoelectronic and birefringence properties of weakly $\mathrm{Mg}$ doped $\mathrm{ZnO}$ thin films prepared by s

optical properties of zn1-xmgxo nanocomposite thin films. Solar Energy Materials and Solar Cells 93, 193-198 (2009). https://doi.org/10.1016/j. solmat.2008.09.039

[61] Sorar, I., Saygin-Hinczewski, D., Hinczewski, M., Tepehan, F.Z.: Optical and structural properties of si-doped zno thin films. Applied Surface Science 257(16), 7343-7349 (2011). https://doi.org/10.1016/j.apsusc.2011. 03.142 

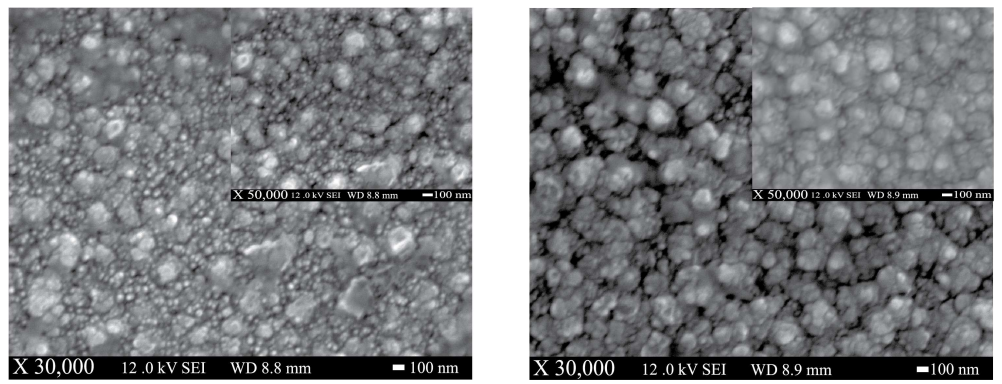

Fig. 8 (left) SEM images of the undoped $\mathrm{ZnO}$ thin film, (right) SEM images of the $\mathrm{Zn}_{0.95} \mathrm{Mg} 0.05 \mathrm{O}$ thin films at $30 \mathrm{k} \times$ and $50 \mathrm{k} \times$, big and small picture respectively. 

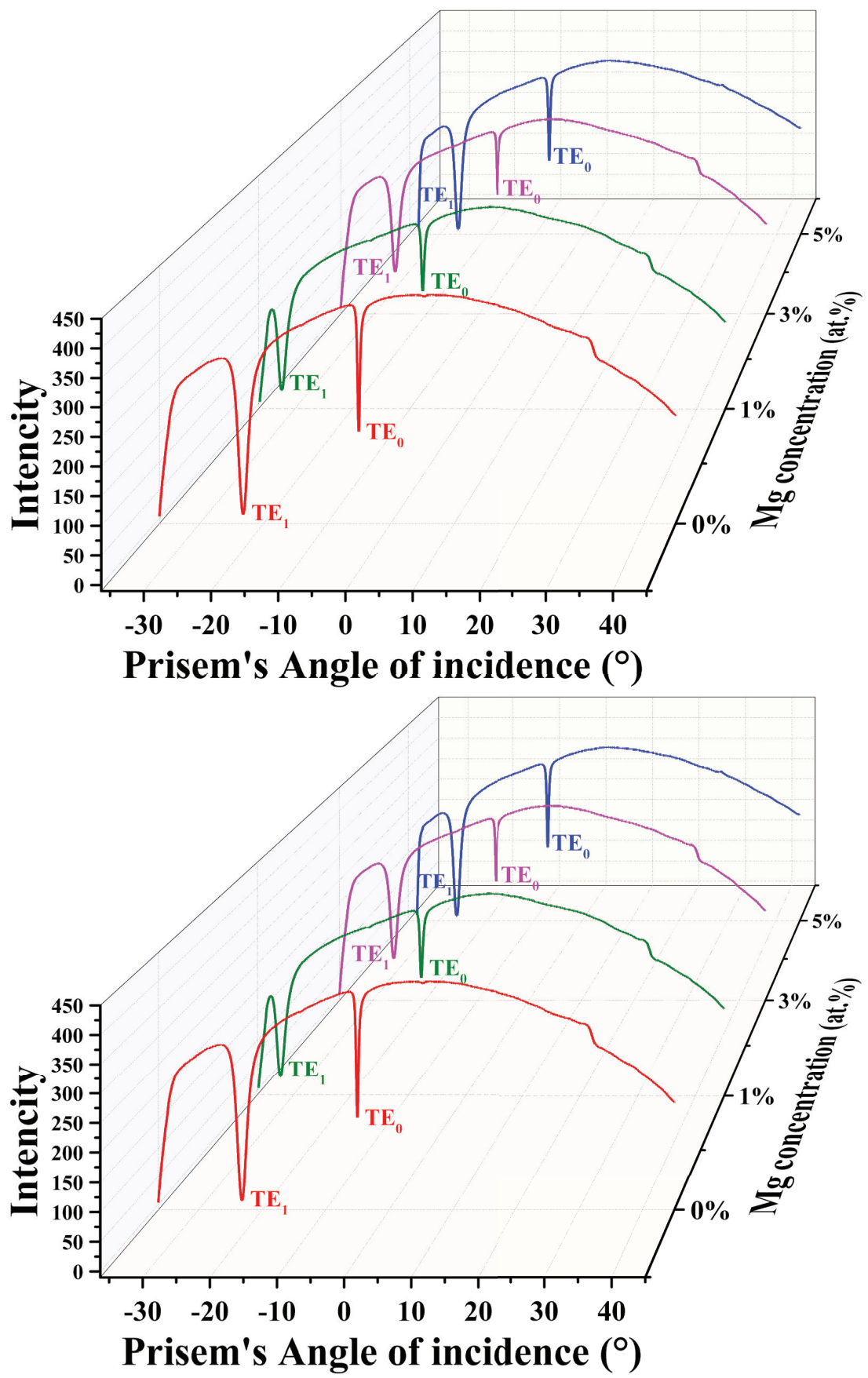

Fig. 9 M-lines intensity vs angle of incident for the deposited doped and undoped films in both Transverse Electric (TE) and Transverse Magnetic (TM). 

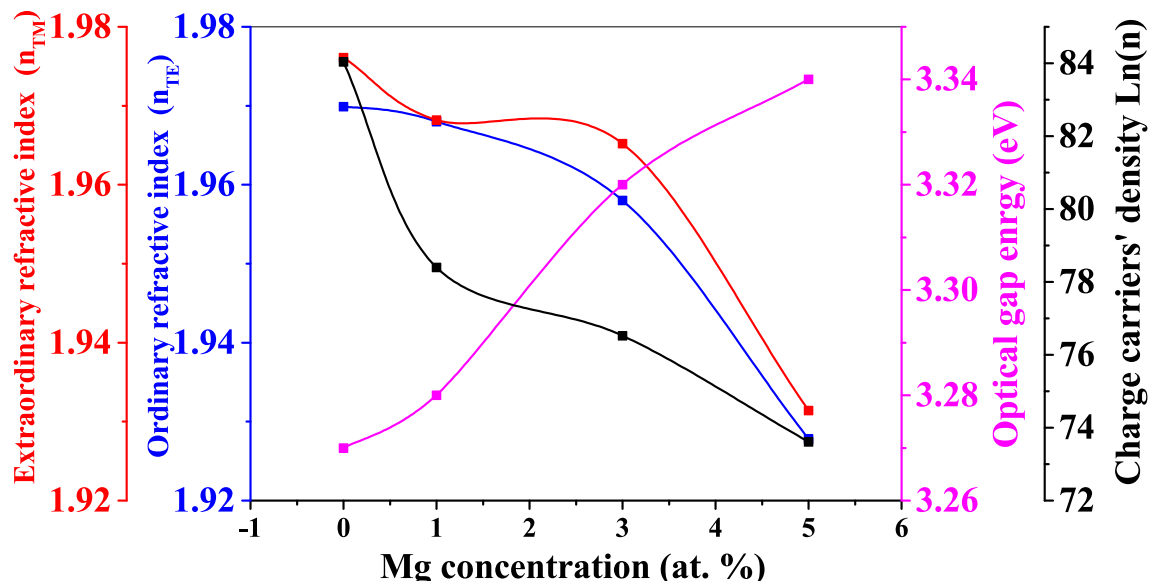

Fig. 10 Ordinary $\left(\mathrm{n}_{\mathrm{TE}}\right)$ and extraordinary $\left(\mathrm{n}_{\mathrm{TM}}\right)$ refractive indices, optical gap energy and charge carriers' density as a function of $\mathrm{Mg}$ concentration. 
Springer Nature $2021 \mathrm{IAT}_{\mathrm{E} X}$ template

\title{
Optoelectronic and birefringence properties of weakly $\mathrm{Mg}$ doped $\mathrm{ZnO}$ thin films prepared by spray pyrolysis
}

\author{
Yassine Bouachibaa ${ }^{1}$, Abdelouadoud \\ Mammeri $^{2 *}$, Abderrahmane Bouabellou ${ }^{2}$, Oualid \\ Rabia $^{1}$, Saber Saidi ${ }^{1}$, Adel Taaboucheb ${ }^{2}$, Badis Rahal ${ }^{3}$, Lyes \\ Benharrat $^{4}$, Hacene Serrar ${ }^{5}$ and Moukhtar Boudissa ${ }^{6}$ \\ ${ }^{1}$ Laboratoire Technologie des Matériaux Avancés,Ecole Nationale \\ Polytechnique de Constantine Malek BENNABI,BP 75A RP,Ali \\ Mendjeli, 25000, Constantine, Algérie. \\ ${ }^{2 *}$ Laboratoire Couches Minces et Interfaces, Université de Fréres \\ Mentouri Constantine 1, Constantine, 25000, Constantine, \\ Algérie. \\ ${ }^{3}$ Nuclear Techniques Division, Nuclear Research Center of \\ Algiers, 2 Bd, Frantz Fanon, BP 399, 16000, Algiers, Algeria. \\ ${ }^{4}$ Research Center in Semiconductors Technology for \\ Energy-CRTSE, 02, Bd. Dr. Frantz Fanon, B.P. 140,7 Merveilles, \\ 16038, Algiers, Algeria. \\ ${ }^{5}$ Research Center in Industrial Technologies (CRTI), BP 64 \\ Cheraga, Alger, Algeria. \\ ${ }^{6}$ ENMC Laboratory, Department of Physics, Faculty of Science, \\ University Ferhat Abbas, Setif, 19000, Algeria. \\ ${ }^{*}$ Corresponding author(s). E-mail(s): \\ abdelouadoud.mammeri@gmail.com; \\ Contributing authors: ybouachiba@gmail.com; a_ \\ bouabellou@yahoo.fr; oualidrabia28@gmail.com; \\ saber18saidi@gmail.com; adelphm@gmail.com; b.rahal@crna.dz; \\ benharrat.lyes@crtse.dz; serrarhacene@gmail.com; \\ mokhtar.bousissa@univ-setif.dz;
}


Springer Nature $2021 \mathrm{LAT}_{\mathrm{E}} \mathrm{X}$ template

2

Article Title

\section{Introduction}

Zinc Oxide $(\mathrm{ZnO})$ is is a multipurpose semiconductor with many uses such as ultra-capacitor electrode [? ], spintronic devices [? ], multigas sensing [? ? ? ?], piezoelectric devices [?], ultra-violet LEDs [? ], detectors [?] as well as waveguides [? ? ? ]. In its thin film form, $\mathrm{ZnO}$ has a large adaptation to several deposition methods such as chemical vapor deposition [?], pulsed laser deposition [?], spray pyrolysis [?], dip-coating [?] and electrochemical deposition [?]. ZnO has very interesting characteristics for application in electronics and optoelectronics devices, especially its exciton binding energy of $60 \mathrm{meV}$ at $300 \mathrm{~K}$, a wide direct band gap of $3.37 \mathrm{eV} \mathrm{[?} \mathrm{].} \mathrm{In} \mathrm{addition} \mathrm{to} \mathrm{an} \mathrm{ordinary} \mathrm{and}$ extraordinary refractive indexes of $n_{e}=2.006$ and $n_{o}=1.990$ respectively [?]. To modify its electrical properties, $\mathrm{ZnO}$ was doped with Group III elements such as $\mathrm{Al}, \mathrm{Ga}$, and In who acted as donor dopants to reinforce its $n$-type electrical nature, and group V elements such as N, P, As and Sb who acted as acceptor dopants which changed $\mathrm{ZnO}$ to be a $p$-type semiconductor [?]. Controlling the refractive index of $\mathrm{ZnO}$ thin films was achieved by several ways including thermal annealing [? ] and doping with In [? ], Te, $\mathrm{N} \mathrm{[?]} \mathrm{and} \mathrm{Mg}$ $[?]$. However, the effect of dopants on the optical and electrical properties of $\mathrm{ZnO}$ is still not well understood.

Tailoring $\mathrm{ZnO}$ optical and electrical properties via dopants while maintaining high quality films especially using spray pyrolysis is very attractive to both scientists and technology developers as it offers a control over several experimental parameters, it is cheap, uncomplicated and environmentally friendly.

Wurtzite $\mathrm{Mg}_{\mathrm{x}} \mathrm{Zn}_{1-\mathrm{x}} \mathrm{O}$ alloy is very interesting due to the high solubility of $\mathrm{Mg}$ in the $\mathrm{ZnO}$ wurtzite matrix (up to 30\%) [?] ]. Moreover, it offers control over a range of optical and electrical properties of $\mathrm{ZnO}$ such as widening of the optical gap energy up to $0.85 \mathrm{eV}$ [?] , consequently, it can be used for multiple purposes such as a top layer in $\mathrm{Mg}_{\mathrm{x}} \mathrm{Zn}_{1-\mathrm{x}} \mathrm{O} / \mathrm{ZnO}$ multilayer $\mathrm{UV}$ photodetector [?] and high mobility $\mathrm{MgZnO} / \mathrm{ZnO}$ thin film transistor [?] to name few. Concerning the waveguiding properties, little attention has been paid to wurtzite $\mathrm{MgZnO}$ as a waveguide, however, $\mathrm{MgZnO}$ was used as a buffer layer for $\mathrm{ZnO}$ waveguide thin film [?]. In an other work, a potential use of $\mathrm{MgZnO}$ cubic rocksalt-type

phase as a wave guide was reported $\mathrm{Yu}$ et al. [? ]. Wurtzite $\mathrm{Mg}_{\mathrm{x}} \mathrm{Zn}_{1-\mathrm{x}} \mathrm{O}$ thin film alloy refractive index was previously studied but there is still work to be done, as there are opposite results regarding the birefringence which is found to be negative in some studies [? ?] and positive in another study[?].

In this work, we engaged in the investigation of the relations between the refractive index, the gap energy and the charge carriers' density in addition to the birefringence of $\mathrm{Mg}_{\mathrm{x}} \mathrm{Zn}_{1-\mathrm{x}} \mathrm{O}$ thin films deposited by spray pyrolysis on glass substrate. 
Springer Nature 2021 LATEX template

Article Title

\section{Results and Discussion}

\subsection{XRD analysis}

From Figure ??a we can see clearly that all films exhibit a crystalline hexagonal wurtzite structure (JCPDS card no. 00-036-1451) with the quasi-predominant of (002) peak indicating the preferential growth of undoped and $\mathrm{Mg}$ doped $\mathrm{ZnO}$ thin films through the c-axis direction. However, weak intensity peaks of other crystalline directions were observed in the following positions $31.96^{\circ}(100)$, $36.56^{\circ}(101), 47.87^{\circ}(102), 63.17^{\circ}(103)$ and $72.85^{\circ}(004)$. The peak (002) experienced a shift towards higher angles (Figure ??b) over $\mathrm{Mg}$ doping which was reported by a number of authors [? ? ? ], and it is due to the difference in the ionic radius between $\mathrm{Mg}^{+2}(0.57 \AA)$ and $\mathrm{Zn}^{+2}(0.60 \AA)$ [?]. This difference is directly related to the compression strain on the main axes of the wurtzite structure $a$ and $c$. Previously, Chang et al. [? ] reported also similar compression strain in their sputtered $\mathrm{MgZnO}$ thin films which were interpreted by good substitution between $\mathrm{Mg}$ and $\mathrm{Zn}$ ions.

The grain size can be calculated by Debye-Scherrer formula [? ]:

$$
D=\frac{K \lambda}{\beta \cos (\theta)}
$$

where $\lambda$ is the wavelength of the incident $\mathrm{X}$-ray, $\theta$ is the Bragg's angle, $\mathrm{K}$ is the shape factor ( 0.9 for gaussian fit), and $\beta$ is the Full Width at Half Maxima (FWHM) of the peaks. The crystallite size, lattice parameters, and strain axes are tabulated in table 1 . It should be noted that there was no significant change in the average crystallite size $\left(33.13 \mathrm{~nm}\right.$ for $\mathrm{Mg}_{0} \mathrm{Zn}_{1} \mathrm{O}$ film and an average of $33.03 \mathrm{~nm}$ for the $\mathrm{Mg}_{\mathrm{x}} \mathrm{Zn}_{1-\mathrm{x}} \mathrm{O}$ films), and the minus sign of the strain values $\left(\epsilon_{a}\right.$ and $\left.\epsilon_{c}\right)$ approves the compression nature of the strain. To calculate lattice parameter $c$ of the thin films we used the Bragg's law (with $\mathrm{n}=1$ ) and the $d$ spacing of wurtzite structure.

\section{$2.2 \mathrm{UV}-\mathrm{V}$ is measurements}

The transmittance of the thin films was slightly enhanced on average with the introduction of $\mathrm{Mg}$ in the visible region (400-800 $\mathrm{nm}$ ). The limit of the absorption zone was shifted to smaller wavelengths which renders the thin films to be more dielectric as $\mathrm{Mg}$ doping is increased, this effect is directly related to the blue shift of the band gap and it was approximated for each film using the Tauc's plot:

$$
\alpha h \nu=A\left(h \nu-E_{g}\right)^{n}
$$

where $h \nu$ is the photon energy, $E_{g}$ is the gap energy, A is constant, and $n$ equals $\frac{1}{2}$ since $\mathrm{ZnO}$ has a direct band gap. The widening of the optical band gap could be ascribed to the difference in electronegativity between $\mathrm{Zn}^{+2}$ and $\mathrm{Mg}^{+2}$ ions [? ? ? ]. In similar study, Al-Ghamdi [? ] reported this correlation between the optical band gap energy and the electronegativity in his work about amorphous $\mathrm{Se}_{96-\mathrm{x}} \mathrm{Te}_{4} \mathrm{Ag}_{\mathrm{x}}$ thin films. 
Springer Nature $2021 \mathrm{LAT}_{\mathrm{E}} \mathrm{X}$ template

In fact, it should be noted that both the electronegativity and electron affinity are directly related [? ]. In this way Figure 4 presents the calculated optical

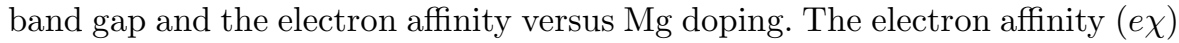
was quantitatively calculated using Vegard's law [?]:

$$
e \chi\left(M g_{x} Z n_{1-x} O\right)=e \chi(Z n O)-(e \chi(Z n O)-e \chi(M g O)) x
$$

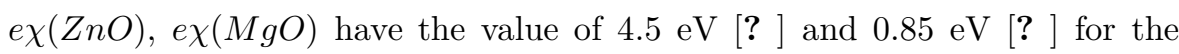
electron affinity of $\mathrm{ZnO}$ and $\mathrm{MgO}$ respectively. Previously, iskenderoglu et al. [? ] approved experimentally by UPS technique the inverse relation between the gap energy and the electron affinity of sprayed $\mathrm{MgZnO}$ alloy thin film, with $\mathrm{Mg}$ doping ranging from 0 to $15 \%$.

\subsection{Photoluminescence}

The room temperature photoluminescence spectra were shown in Figure 5 The undoped thin film had four peaks at $381(3.25 \mathrm{eV}), 416(2.98 \mathrm{eV}), 441(2.81$ $\mathrm{eV})$ and $505 \mathrm{~nm}(2.46 \mathrm{eV})$ which were explained by: the emission corresponding to gap recombination, zinc interstitial $\left(\mathrm{Zn}_{\mathrm{i}}\right)$, oxygen vacancies $\left(\mathrm{V}_{\mathrm{O}}\right)$ and donor $\mathrm{V}_{\mathrm{O}}$ - acceptor $\mathrm{V}_{\mathrm{Zn}}$ recombination respectively [? ? ]. The same peaks were observed also in $\mathrm{Mg}_{0.01} \mathrm{Zn}_{0.99} \mathrm{O}$ except a blue shift of the 380 peak to 381 $\mathrm{nm}(3.26 \mathrm{eV})$. The $\mathrm{Mg}_{0.03} \mathrm{Zn}_{0.97} \mathrm{O}$ thin film had three peaks $379(3.27 \mathrm{eV})$, $416(2.81 \mathrm{eV})$, and $492 \mathrm{~nm}(2.52 \mathrm{eV})$ and they were attributed to gap recombination, zinc interstitial $\left(\mathrm{Zn}_{\mathrm{i}}\right)$ [?] and oxygen vacancy $\left(\mathrm{V}_{\mathrm{O}}\right)$ [?] respectively. Finally the $\mathrm{Mg}_{0.05} \mathrm{Zn}_{0.95} \mathrm{O}$ thin film exhibited two peaks at $378(3.28 \mathrm{eV})$ and $503 \mathrm{~nm}(2.47 \mathrm{eV})$ and they were manifestations of gap and donor $\mathrm{V}_{\mathrm{O}}$ - acceptor $\mathrm{V}_{\mathrm{Zn}}$ recombinations [? ? ]. The blue shift of the near band edge emission from the PL peaks was in consistency with the UV visible calculations of the optical band gap, however, it was at a lower rate which was explained by stokes shift [?].

\subsection{Electrical measurements}

Figure 6 demonstrates the near isotropic electric transportation of the deposited films which could be attributed to the fact that the films have the predominant orientation (002) of the wurtzite structure [? ].

The free charge carriers density decreases from $3.146 \times 10^{18}$ for the undoped film to $9.273 \times 10^{13} \mathrm{~cm}^{-3}$ for $\mathrm{Mg}_{0.05} \mathrm{Zn}_{0.95} \mathrm{O}$ film. In parallel, the resistivity increased from 109 to $1268 \Omega \mathrm{cm}$ and the mobility increases from 0.01821 to $53.08 \mathrm{~cm}^{2} /$ (V.s). The decreased charge carriers' density could be attributed to the fact that the conduction band (CB) of pure $\mathrm{ZnO}$ consists mainly of $\mathrm{O}_{2 \mathrm{p}}$ and $\mathrm{Zn}_{4 \mathrm{~s}}$ states [? ? ], so the introduction of $\mathrm{Mg}$ in $\mathrm{ZnO}$ thin films will reduce the $\mathrm{Zn}_{4 \mathrm{~s}}$ state and introduce $\mathrm{Mg}_{3 \mathrm{p}}$ state which has high energy relative to the $\mathrm{Zn}_{4 \mathrm{~s}}$ [? ? ]. Moreover, the widening in the optical bang gap energy discussed previously, could also influence the free charge carriers' density since the electrons passing from the valance band must have higher energy to access the conduction band. 
Springer Nature $2021 \mathrm{LAT}_{\mathrm{E} X}$ template

Article Title

\subsection{Surface morphology}

Figure 8 shows the morphology of undoped and 5 at. \% doped $\mathrm{ZnO}$ thin films. The undoped (Figure 8a) thin film shows an inhomogeneous and dense structure with granular mixture of small grains and large aggregates. The size of the small grains varies from $\sim 20$ to $80 \mathrm{~nm}$ and that of the aggregates reaches $\sim 200-300 \mathrm{~nm}$. Suggesting the doped sample (Figure $8 \mathrm{~b}$ ), it is evident that magnesium has a tendency to promote the phenomenon of coalescence. This doped film shows a less dense and relatively homogeneous morphology with large aggregates whose size varies from $\sim 200$ to $500 \mathrm{~nm}$.

No cracks nor empty holes were observed on the surface of the films, revealing the high quality of our films.

\subsection{M-lines measurements}

The M-lines measurements demonstrate the guiding modes present in the films. All films have four guiding modes $\left(\mathrm{TE}_{0}, \mathrm{TE}_{1}, \mathrm{TM}_{0}\right.$, and $\left.\mathrm{TM}_{1}\right)$ two for each optical polarization (Transverse Electric mode (TE) and Transverse Magnetic mode $(\mathrm{TM})$ ) as illustrated in Figure 9. Using the dispersion equations for TE and TM polarizations, the optogeometric parameters can be calculated [? ? ? ]. The effective indices, the films thicknesses, and the birefringence values are presented in Table 2.

Figure 10 illustrate the variation of $\mathrm{n}_{\mathrm{TE}}, \mathrm{n}_{\mathrm{TM}}$, optical gap energy and free charge carriers' density as a function of the $\mathrm{Mg}$ concentration. The slight difference between $n_{T E}$ and $n_{T M}$ confirms the birefringence behavior of our films. This makes the guided waves traveling during the TE mode in the plane perpendicular to the $c$-axis of the wurtzite structure submit to an ordinary refractive index $\left(\mathrm{n}_{\mathrm{TE}}\right)$ and during the TM mode to an extraordinary one $\left(\mathrm{n}_{\mathrm{TM}}\right)$ [?]. Both $\mathrm{n}_{\mathrm{TE}}$ and $\mathrm{n}_{\mathrm{TM}}$ were found to decreased over Mg doping. This behavior seems to be in good agreement with the broadening of the optical band gap and the depletion of the conduction band free charge carriers' (Figure 10) [?]. The birefringence was measure to be positive for all films which is a good indication for the unchanging orientation of the bond with the replacement of $\mathrm{Zn}^{+2}$ by $\mathrm{Mg}^{+2}$ [? ?].

The inverse relation between the optical gap energy, the resistivity and the refractive index as $\mathrm{Mg}$ content increased in the $\mathrm{ZnO}$ thin film was also observed by Kaushal et al. [?]. The same fact has been reported by Teng et al. [?] for $\mathrm{Mg}$-doped $\mathrm{ZnO}$ thin films prepared by pulsed laser deposition. In similar study, Sorar et al. [?] found that the ordinary refractive index generally decreases with the increase of the $\mathrm{Si}$ doping in $\mathrm{ZnO}$ thin films prepared by sol-gel and annealed at $350{ }^{\circ} \mathrm{C}$ and $550{ }^{\circ} \mathrm{C}$ whereas their optical band gap energy was found to be blue shifted. 
Table 1 The information obtained and calculated from the XRD spectra.

\begin{tabular}{|c|c|c|c|c|c|c|c|}
\hline Sample & $2 \theta$ (degree) & $d$ spacing $(\AA)$ & Crystallite size (nm) & $a(\AA)$ & $c(\AA)$ & $\epsilon_{a}\left(10^{-3}\right)$ & $\epsilon_{c}\left(10^{-3}\right)$ \\
\hline $\mathrm{Mg}_{0.00} \mathrm{Zn}_{1.00} \mathrm{O}$ & 34.75 & 2.580 & 33.13 & 3.2306 & 5.1592 & -3.4241 & -5.4746 \\
\hline $\mathrm{Mg}_{0.01} \mathrm{Zn}_{0.99} \mathrm{O}$ & 34.77 & 2.455 & 31.26 & 3.2240 & 5.1560 & -5.4601 & -6.0915 \\
\hline $\mathrm{Mg}_{0.03} \mathrm{Zn}_{0.97} \mathrm{O}$ & 34.77 & 2.456 & 31.30 & 3.2256 & 5.1560 & -4.9665 & -6.0915 \\
\hline $\mathrm{Mg}_{0.05} \mathrm{Zn}_{0.95} \mathrm{O}$ & 34.78 & 2.577 & 35.83 & 3.2298 & 5.1547 & -3.6709 & -6.3421 \\
\hline
\end{tabular}


Table 2 Optogeometric Properties of the deposited thin films.

\begin{tabular}{c|c|c|c|c|c|c|c|c|c|c}
\hline \multirow{2}{*}{ Sample } & \multicolumn{4}{|c|}{ Effective index $\pm 10^{-4}$} & \multicolumn{2}{c|}{ Refractive index $10^{-4}$} & Thickness TE & Thickness TM & Birefringence \\
\cline { 2 - 10 } & $\mathrm{TE}_{0}$ & $\mathrm{TE}_{1}$ & $\mathrm{TM}_{0}$ & $\mathrm{TM}_{1}$ & $\mathrm{n}_{\mathrm{TE}}$ & $\mathrm{n}_{\mathrm{TM}}$ & $\pm 0.1 \mathrm{~nm}$ & $\pm 0.1 \mathrm{~nm}$ & $\left(\mathrm{n}_{\mathrm{TM}}-\mathrm{n}_{\mathrm{TE}}\right)$ \\
\hline $\mathrm{Mg}_{0.00} \mathrm{Zn}_{1} .00 \mathrm{O}$ & 1.8923 & 1.6565 & 1.8793 & 1.6033 & 1.9699 & 1.9761 & 436.1 & 452.1 & 0.0062 \\
\hline $\mathrm{Mg}_{0.01} \mathrm{Zn}_{0.99} \mathrm{O}$ & 1.8758 & 1.5994 & 1.8539 & 1.5486 & 1.9680 & 1.9682 & 347.4 & 382.6 & 0.0002 \\
\hline $\mathrm{Mg}_{0.03} \mathrm{Zn}_{0.97} \mathrm{O}$ & 1.8738 & 1.6203 & 1.8581 & 1.5647 & 1.9580 & 1.9652 & 413.1 & 426.3 & 0.0072 \\
\hline $\mathrm{Mg}_{0.05} \mathrm{Zn}_{0.95} \mathrm{O}$ & 1.8451 & 1.5981 & 1.8278 & 1.5494 & 1.9278 & 1.9314 & 417.7 & 433.7 & 0.0036 \\
\hline
\end{tabular}




\section{Tables}

\section{Figures}

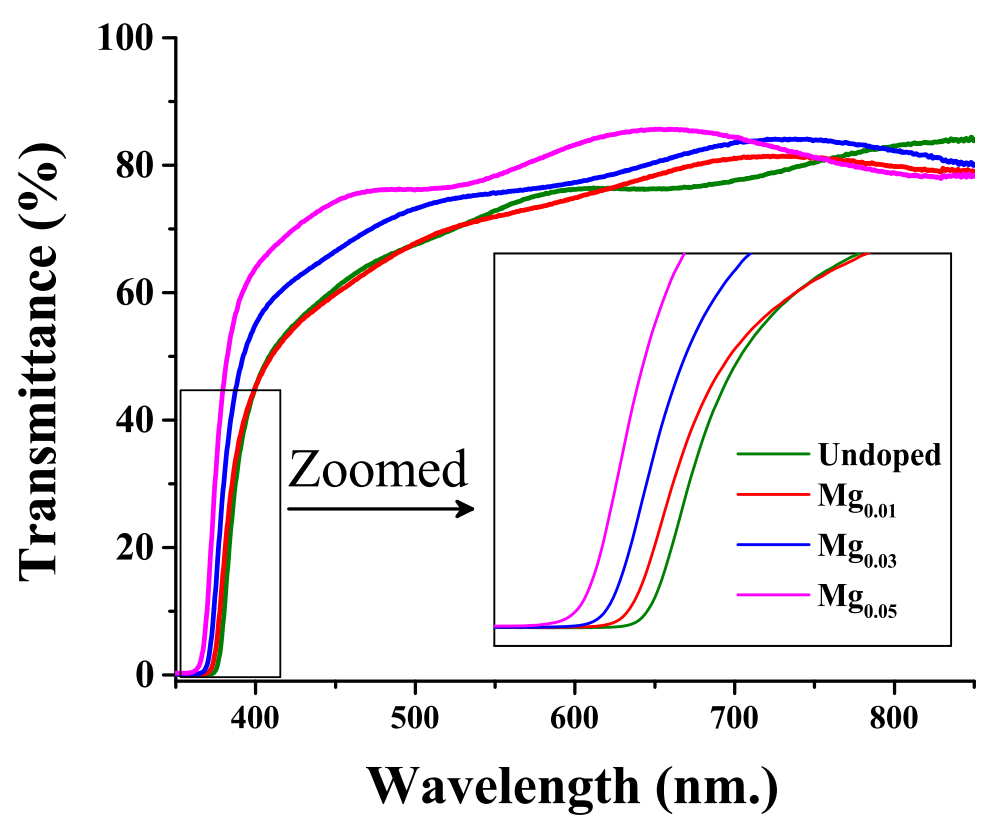

Fig. 2 Transmittance spectra of pure and doped $\mathrm{ZnO}$ thin films zoomed in the absorption region.

\section{Methods}

The sprayed solution for the undoped $\mathrm{ZnO}$ thin films was prepared by dissolving the proper amount of dihydrate zinc acetate $\left[\mathrm{Zn}\left(\mathrm{CH}_{3} \mathrm{CO}_{2}\right)_{2} \cdot 2 \mathrm{H}_{2} \mathrm{O}\right]$ in $99.98 \%$ pure methanol to obtain $0.1 \mathrm{M}$ solution that was submitted to a constant stirring at $60{ }^{\circ} \mathrm{C}$ for $45 \mathrm{~min}$ on a magnetic stirrer. Concerning the sprayed solution of the $\mathrm{Mg}$ doped $\mathrm{ZnO}$ thin films, we maintained the same parameters with the use of magnesium chloride $\left[\mathrm{Mg}\left(\mathrm{CH}_{3} \mathrm{CO}_{2}\right)_{2} \cdot 4 \mathrm{H}_{2} \mathrm{O}\right]$ as $\mathrm{Mg}$ precursor, and each time the proper amount was added to $0.1 \mathrm{M}$ methanol solutions of $\mathrm{Zn}\left(\mathrm{CH}_{3} \mathrm{CO}_{2}\right)_{2} \cdot 2 \mathrm{H}_{2} \mathrm{O}$ to produce the following contents of zinc and magnesium: $\mathrm{Mg}_{\mathrm{x}} \mathrm{Zn}_{1-\mathrm{x}} \mathrm{O}$ with x equals $0.01,0.03$ and 0.05 .

An ordinary glass substrate were ultra-sonically cleaned in a 1:1 mixture of acetone and ethanol for $15 \mathrm{~min}$ and left to dry in air. The films were deposited using spray pyrolysis system. The deposition temperature was $450{ }^{\circ} \mathrm{C}$. 
In order to characterize our thin films, multiple techniques were used: Philips PANalytical X'Pert Pro diffractometer with a wave length of $1.5406 \AA$, environmental scanning electron microscope Philips XL30 ESEM FEG and for the electrical properties Ecopia HMS-3000 hall effect measurement system, finally for the optical measurements, Metricon 2010/M Prism (rutile $\mathrm{TiO}_{2}: \mathrm{n}_{\mathrm{e}}=2,8639$ and $\mathrm{n}_{\mathrm{o}}=2.5822$ at $632,8 \mathrm{~nm}$ with an angle of $A_{p}=44,60^{\circ}$ ) Coupler was used to couple $632.8 \mathrm{~nm}$ HeNe laser light into air $/ \mathrm{Mg}_{\mathrm{x}} \mathrm{Zn}_{1-\mathrm{x}} \mathrm{O} /$ glass waveguide and Shimadzu UV-3101PC Spectrophotometer.

\section{Conclusion}

$\mathrm{Mg}$ doped $\mathrm{ZnO}$ thin films were successfully deposited on glass substrate via spray pyrolysis at $450{ }^{\circ} \mathrm{C}$. The XRD characterization showed highly $c$ oriented thin films with a decrease in $a$ and $c$ as the $\mathrm{Mg}$ concentration increased in the thin films. The undoped thin film had a multisize grain distribution meanwhile the $\mathrm{Mg}_{0.05} \mathrm{Zn}_{0.95} \mathrm{O}$ had a more homogeneous grain distribution. $\mathrm{Mg}$ doping in the $\mathrm{ZnO}$ films led to a blue shift of the optical band gap energy and a depletion of the conduction band due to the drop in free carriers' density that had a direct effect on the ordinary and the extraordinary refractive indexes that were found to decrease. The birefringence of a crystal depends on multiple factors such as strain, defects charge carriers' density, bound orientation and so on, therefore it will change from papers to papers with the change of deposition method especially.

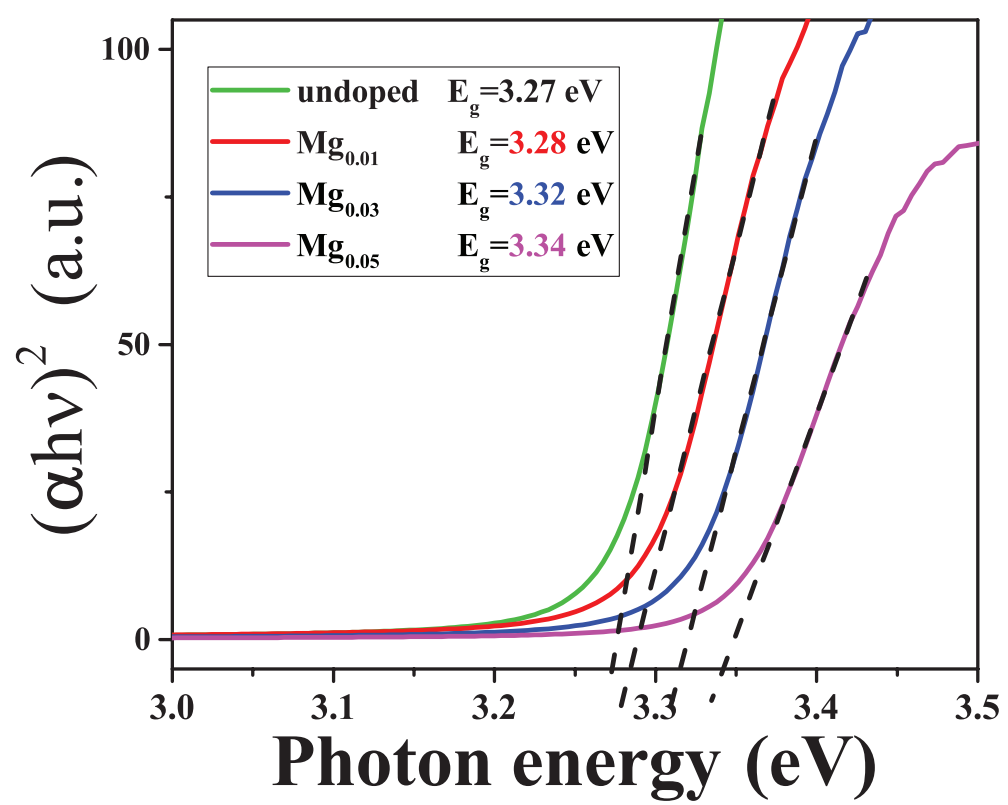

Fig. 3 Tauc's plot for the undoped and doped $\mathrm{ZnO}$ thin films. 


\section{Declarations}

- Funding: Not applicable

- Conflict of interest/Competing interests: The authors declare that they have no conflict of interest.

- Ethics approval: Not applicable

- Consent to participate: Not applicable

- Consent for publication: Not applicable

- Availability of data and materials: Not applicable

- Code availability: Not applicable

- Authors' contributions: Not applicable

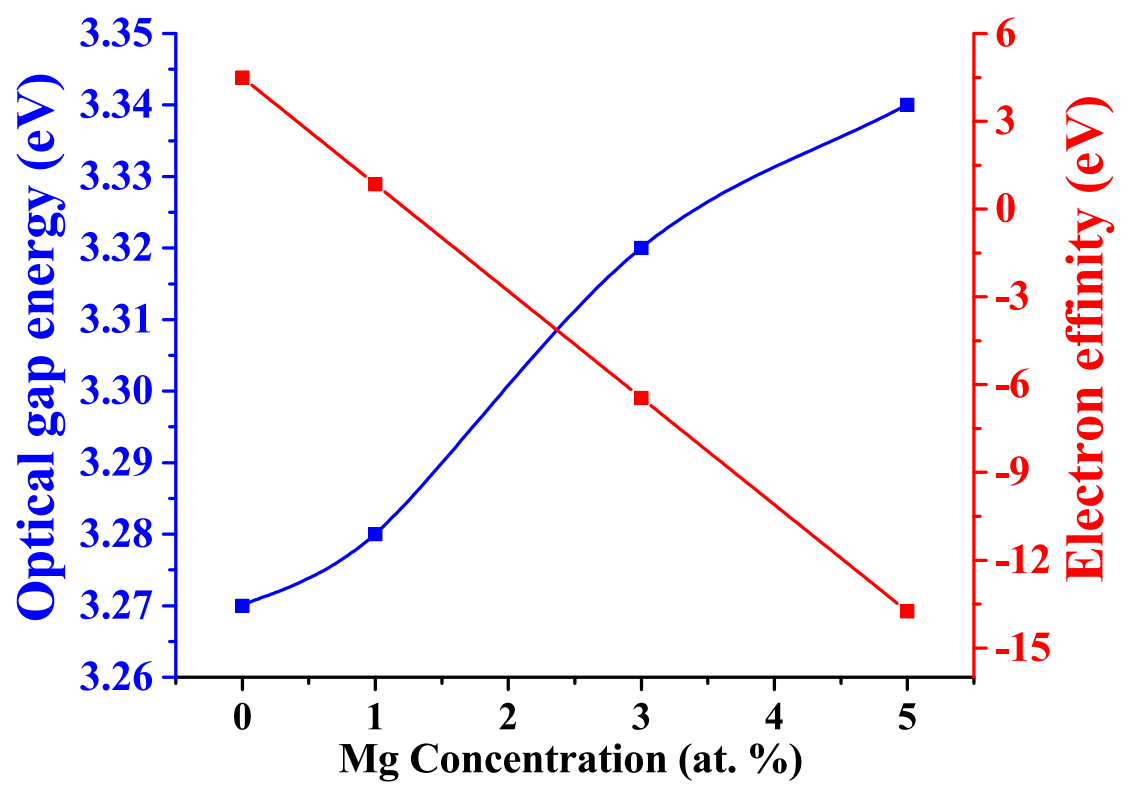

Fig. 4 The evolution of the optical band gap energy and the electron affinity of $\mathrm{Mg}_{\mathrm{x}} \mathrm{Zn}_{1-\mathrm{x}} \mathrm{O}$ thin films as a function of $\mathrm{Mg}$ concentration. 
Springer Nature $2021 \mathrm{LAT}_{\mathrm{E} X}$ template

Article Title
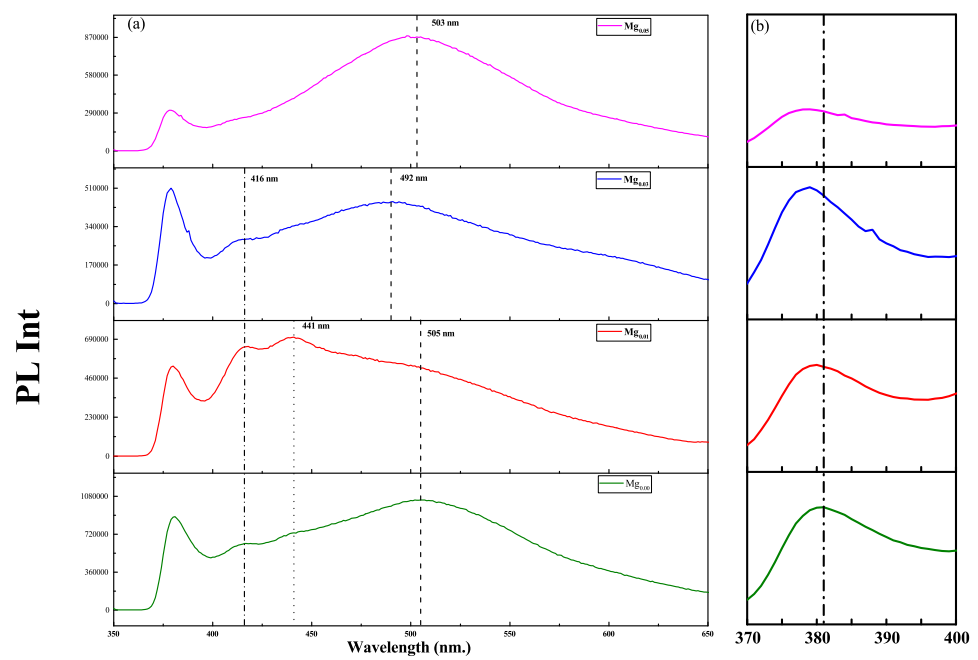

Fig. 5 (a) Room temperature photoluminescence spectra, (b) an emphasis of the excitons recombination peaks
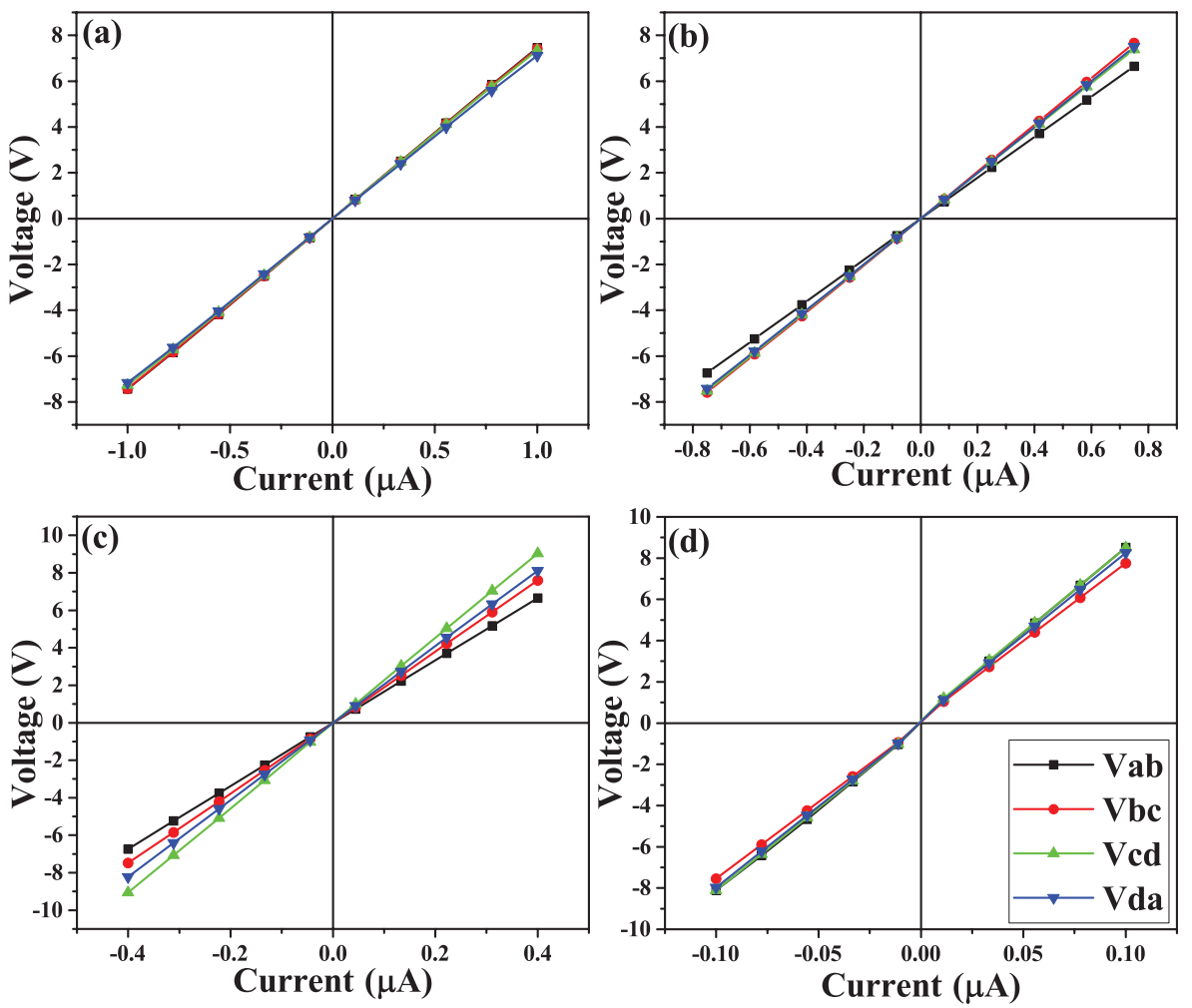

Fig. $6 \mathrm{I}-\mathrm{V}$ measurements for the four thin films: (a) undoped $\mathrm{ZnO}$, (b) $\mathrm{Mg}_{0.01} \mathrm{Zn}_{0.99} \mathrm{O}$, (c) $\mathrm{Mg}_{0.03} \mathrm{Zn}_{0.97} \mathrm{O}$ and (d) $\mathrm{Mg}_{0.05} \mathrm{Zn}_{0.95} \mathrm{O}$. 